\title{
Corrosion Assessment of Candidate Materials for the SHINE Subcritical Assembly Vessel and Components - FY 2015 Report
}

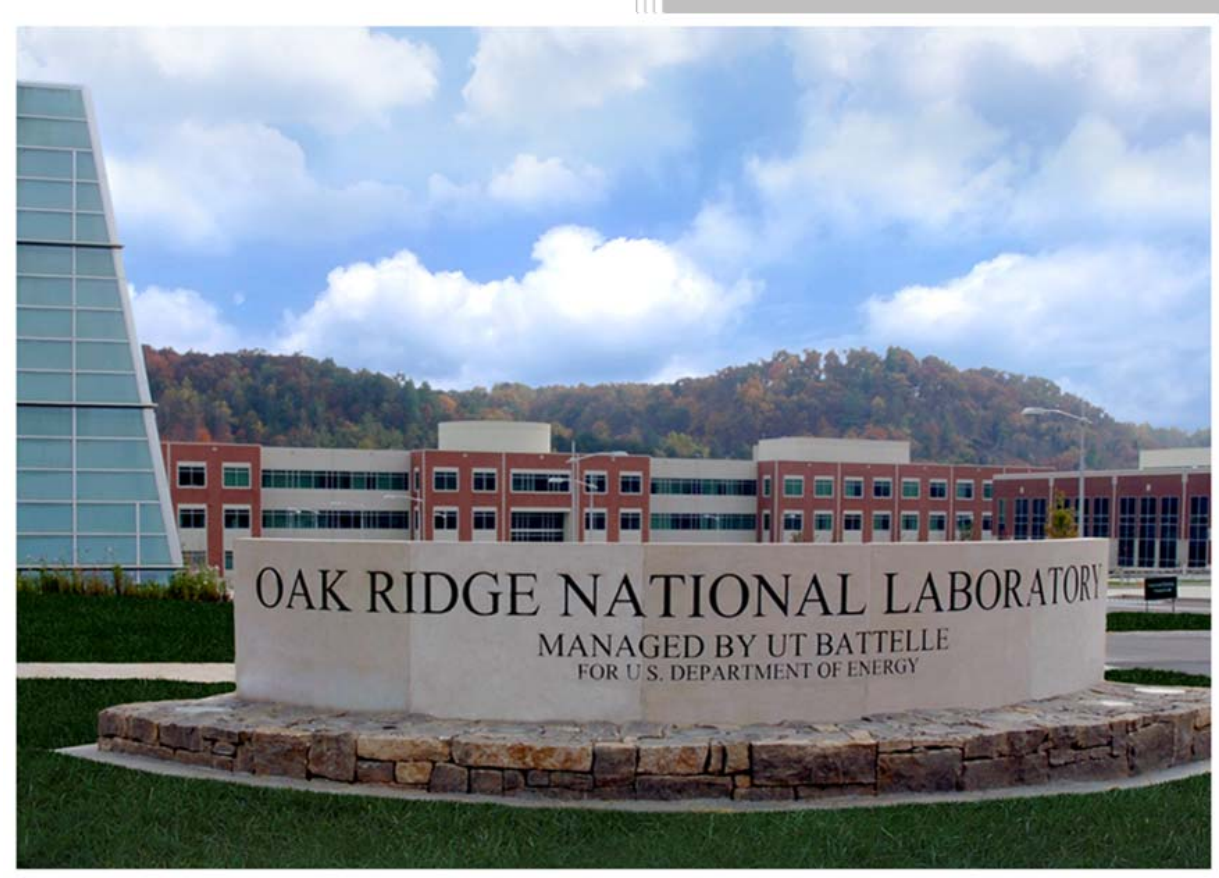

Approved for public release.

S. J. Pawel

Distribution is unlimited.

January 2016 


\title{
DOCUMENT AVAILABILITY
}

Reports produced after January 1, 1996, are generally available free via US Department of Energy (DOE) SciTech Connect.

Website http://www.osti.gov/scitech/

Reports produced before January 1, 1996, may be purchased by members of the public from the following source:

\author{
National Technical Information Service \\ 5285 Port Royal Road \\ Springfield, VA 22161 \\ Telephone 703-605-6000 (1-800-553-6847) \\ TDD 703-487-4639 \\ Fax 703-605-6900 \\ E-mail info@ntis.gov \\ Website http://www.ntis.gov/help/ordermethods.aspx
}

Reports are available to DOE employees, DOE contractors, Energy Technology Data Exchange representatives, and International Nuclear Information System representatives from the following source:

Office of Scientific and Technical Information

PO Box 62

Oak Ridge, TN 37831

Telephone 865-576-8401

Fax 865-576-5728

E-mail reports@osti.gov

Website http://www.osti.gov/contact.html

This report was prepared as an account of work sponsored by an agency of the United States Government. Neither the United States Government nor any agency thereof, nor any of their employees, makes any warranty, express or implied, or assumes any legal liability or responsibility for the accuracy, completeness, or usefulness of any information, apparatus, product, or process disclosed, or represents that its use would not infringe privately owned rights. Reference herein to any specific commercial product, process, or service by trade name, trademark, manufacturer, or otherwise, does not necessarily constitute or imply its endorsement, recommendation, or favoring by the United States Government or any agency thereof. The views and opinions of authors expressed herein do not necessarily state or reflect those of the United States Government or any agency thereof. 


\title{
CORROSION ASSESSMENT OF CANDIDATE MATERIALS FOR THE SHINE SUBCRITICAL ASSEMBLY VESSEL AND COMPONENTS - FY 2015 REPORT
}

\author{
S. J. Pawel
}

Date Published: January 2016

\author{
Prepared by \\ OAK RIDGE NATIONAL LABORATORY \\ Oak Ridge, TN 37831-6283 \\ managed by \\ UT-BATTELLE, LLC \\ for the \\ US DEPARTMENT OF ENERGY \\ under contract DE-AC05-00OR22725
}





\section{CONTENTS}

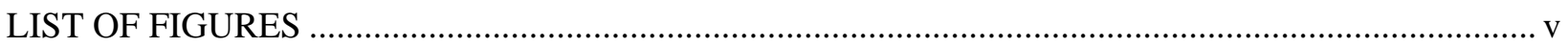

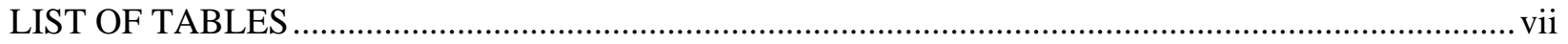

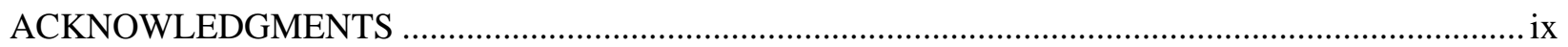

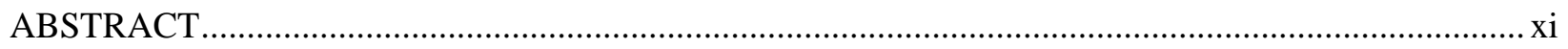

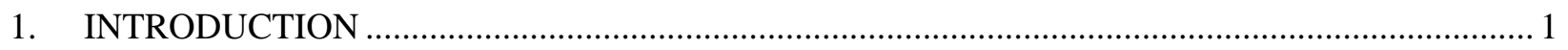

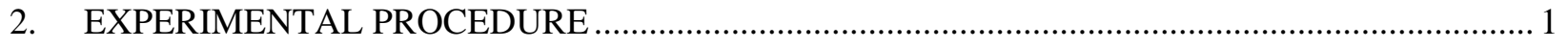

2.1 STRESS-CORROSION CRACKING WITH U-BENDS …................................................. 1

2.2 STRESS-CORROSION CRACKING WITH SLOW-STRAIN RATE TENSILE TESTS ....... 5

2.3 ELECTROCHEMICAL POLARIZATION AND FLUID VELOCITY .................................. 6

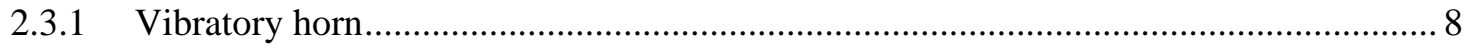

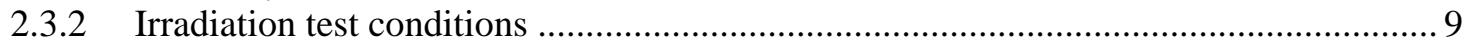

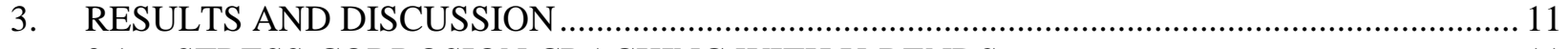

3.1 STRESS-CORROSION CRACKING WITH U-BENDS …............................................. 11

3.2 STRESS-CORROSION CRACKING WITH SLOW-STRAIN RATE TENSILE TESTS ..... 18

3.3 ELECTROCHEMICAL POLARIZATION AND FLUID VELOCITY …............................. 23

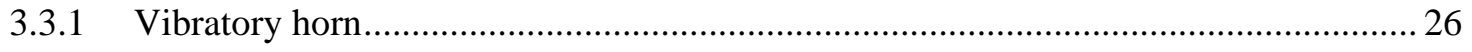

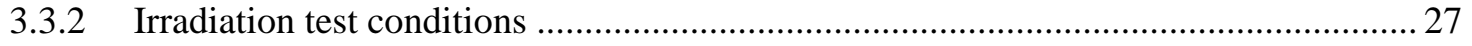

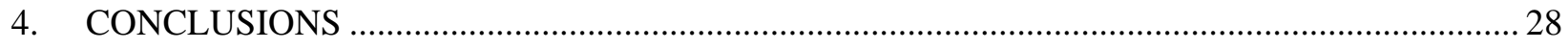

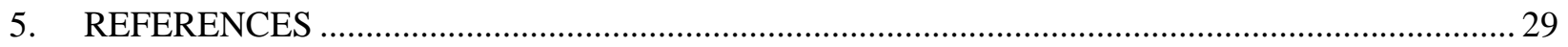





\section{LIST OF FIGURES}

Figure 1. Dimensions of flat stock panels used to generate U-bend specimens. ....................................... 2

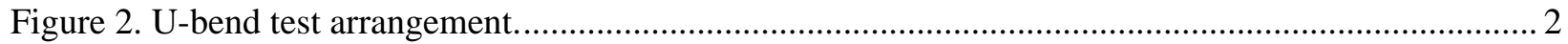

Figure 3. As-machined (left) and pickled (right) specimens of Zr-4 prior to test exposure. ....................... 4

Figure 4. Schematic test cell with photographs of the test cell components and a miniature tensile specimen used for the slow-strain rate tests........................................................................ 6

Figure 5. Electrochemical test cell containing depleted uranyl sulfate solution (yellow) along with a close-up of the rotating disk specimen................................................................................... 7

Figure 6. Schematic representation of the rotating disk electrode arrangement and the fluid motion generated as a function of rotational speed....................................................................... 8

Figure 7. Key components of a vibratory horn (left) and details of a cavitation test specimen

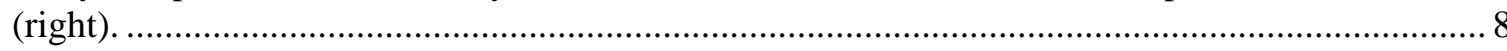

Figure 8. Views of the specimen "tree" and the HFIR/GIF test container vessel and lid.......................... 10

Figure 9. Fully assembled test capsule prior to placement within an over-pack (left) and a mock

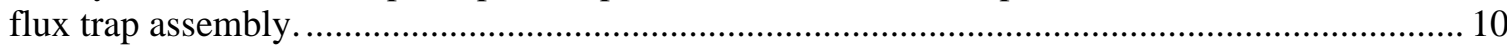

Figure 10. Views of the activity around the spent fuel pool at HFIR during placement of a

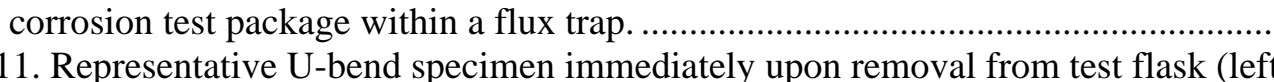

Figure 11. Representative U-bend specimen immediately upon removal from test flask (left)
showing accumulations of depleted uranyl sulfate and the same specimen following cleaning (right).

Figure 12. Post-exposure U-bends of 2304 and 17-4 PH stainless steels showing the contrast in coloration of the surface as a function of alloy type and specimen orientation during the exposure.

Figure 13. Post-exposure 316L stainless steel U-bends showing light golden brown discoloration on the bend apex that was exposed above the solution line.

Figure 14. Post-exposure U-bends of Zr-4 showing variable degrees of development of a golden

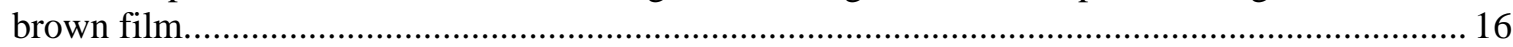

Figure 15. Stress-strain curves for 316L stainless steel as a function of test environment........................ 20

Figure 16. Stress-strain curves for $\mathrm{Zr}-4$ as a function of test environment. ............................................. 20

Figure 17. Fracture surface macrographs (left column) and representative fracture surface detail (right column) for 316L tensile specimens pulled to failure in three different environments.

Figure 18. Fracture surface macrographs (left column) and representative fracture surface detail (right column) for $\mathrm{Zr}-4$ tensile specimens pulled to failure in three different environments.

Figure 19. Schematic representation of the reduction in area for 316L and Zr-4 specimens

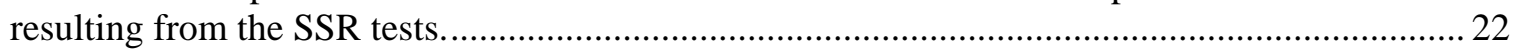

Figure 20. Schematic polarization curve for a material indicating simple passivity. .............................. 24

Figure 21. Schematic changes in polarization behavior that might result from increasing fluid velocity (left) or localized corrosion (right).

Figure 22. Comparison of polarization results at room temperature and zero rotational velocity for alloys in $140 \mathrm{~g} / \mathrm{L}$ dU with $0.1 \mathrm{M}$ sulfuric acid added. ................................................................ 25

Figure 23. Polarization curves for $\mathrm{Zr}-2.5 \mathrm{Nb}$ at room temperature as a function of rotational speed

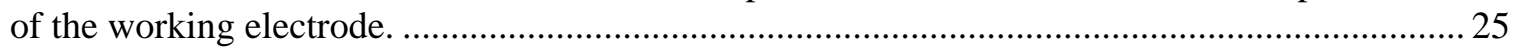

Figure 24. Weight loss as a function of sonication time for the $\mathrm{Zr}-4$ and $316 \mathrm{~L}$ specimens....................... 26

Figure 25. Post-exposure appearance of the specimens exposed to potential radiolysis conditions........... 28 



\section{LIST OF TABLES}

Table 1. Composition (wt. \%) for stainless steel specimens subjected to U-bend testing. .......................... 3

Table 2. Composition (wt. \%) for zirconium-based alloys. ...................................................................... 4

Table 3. Alloy/environment combinations for the U-bend stress corrosion cracking tests ......................... 5

Table 4. Weight change (g) for stainless steel U-bends exposed for a cumulative 20 days (10 days at $80-81^{\circ} \mathrm{C}$ and 10 days at $93-94^{\circ} \mathrm{C}$ ) in the indicated solutions and specimen orientations.......... 15

Table 5. Weight change (g) for zirconium alloy U-bends exposed for a cumulative 20 days (10 days at $80-81^{\circ} \mathrm{C}$ and 10 days at $93-94^{\circ} \mathrm{C}$ ) in the indicated solutions and specimen orientations.

Table 6. Key parameters from the stress-strain curves for 316L stainless steel as a function of test environment

Table 7. Key parameters from the stress-strain curves for 2304 duplex stainless steel as a function of test environment

Table 8. Key parameters from the stress-strain curves for 17-4 PH stainless steel as a function of test environment

Table 9. Key parameters from the stress-strain curves for $\mathrm{Zr}-4$ as a function of test environment 19

Table 10. Key parameters from the stress-strain curves for $\mathrm{Zr}-2.5 \mathrm{Nb}$ as a function of test environment.

Table 11. Relationship between mass loss (steady state and total) and surface roughness in the erosion-corrosion exposure tests.

Table 12. Comparison of corrosion rates $(\mu \mathrm{m} / \mathrm{y})$ derived from weight change resulting from exposures with and without intense gamma radiation (and thus potential radiolysis)..... 



\section{ACKNOWLEDGMENTS}

This research project was sponsored by the US Department of Energy National Nuclear Security Administration under the Office of Material Management and Minimization (M3; formerly known as the Global Threat Reduction Initiative) to support promising technologies for the production of ${ }^{99} \mathrm{Mo}$. The program is managed at Oak Ridge National Laboratory by C. D. Bryan and supported by a number of other individuals owed thanks by the author. In particular, Z. M. Burns performed a number of laboratory corrosion tests and managed laboratory supplies as well as specimen procurement, preparation, and cleaning and handling and also directed operations associated with the HFIR/GIF experiments. T. M. Lowe performed the scanning electron microscopy. J. W. Geringer assisted in experiment planning and administrative duties. N. D. Foster and C. A. Maples provided support associated with procurement and inventory of radioactive materials and associated handling protocol; and K. E. King, B. D. Johnson, and K. P. Curtis performed regular health physics monitoring of the laboratory area as well as various specimens and materials. T. W. Strader and the Health, Safety, and Environment Group provided general support and oversight of the laboratory activities. P. A. Taylor claimed lightly "used" depleted uranyl sulfate solutions as feedstock for another experiment. K. J. Leonard provided zirconium-based materials for specimen making and led the design effort associated with the gamma-irradiation exposure campaign. J. R. Keiser, C. Silva, and B. A. Pint reviewed the manuscript and offered helpful suggestions.

E. N. Van Abel, N. Roberts, and J. Driscoll of SHINE Medical Technologies participated in directing of the laboratory efforts as well as review of the report manuscript. 



\begin{abstract}
In the previous report of this series, a literature review was performed to assess the potential for substantial corrosion issues associated with the proposed SHINE process conditions to produce ${ }^{99}$ Mo. Following the initial review, substantial laboratory corrosion testing was performed emphasizing immersion and vapor-phase exposure of candidate alloys in a wide variety of solution chemistries and temperatures representative of potential exposure conditions. Only very stable passivity and negligibly low corrosion rates were observed in the initial set of testing. Follow-on testing reported here incorporates

- $\quad$ assessment of stress corrosion cracking susceptibility as evaluated by both U-bend specimens (fully immersed and in vapor above solution) and slow-strain rate tests;

- electrochemical polarization to consider passivation characteristics of candidate alloys in both static solutions and as a function of fluid velocity using rotating disk electrodes;

- evaluation of the role of uranium in solution as it applies to potential erosion/corrosion in cavitation conditions; and

- an exposure at the Gamma Irradiation Facility to consider the sensitivity of candidate alloy corrosion in potential radiolysis conditions.

Stress corrosion cracking was not identified in any of the exposures up to 10 days at $80^{\circ} \mathrm{C}$ and 10 additional days at $93^{\circ} \mathrm{C}$. Mechanical properties and specimen fracture face features resulting from slowstrain rate tests further supported a lack of sensitivity of these alloys to stress corrosion cracking. Fluid velocity was found not to be an important variable ( 0 to $\sim 3 \mathrm{~m} / \mathrm{s}$ ) in the corrosion of candidate alloys at room temperature and $50^{\circ} \mathrm{C}$. Uranium in solution was not found to adversely influence potential erosioncorrosion (note that SHINE does not expect cavitation conditions in the process), as uranium-bearing solutions and uranium-free solutions (same $\mathrm{pH}$ and sulfate concentration) generated essentially identical erosion-corrosion results at room temperature. Potentially intense radiolysis conditions slightly accelerated the general corrosion of candidate alloys, but no materials were observed to exhibit an annualized rate above $10 \mu \mathrm{m} / \mathrm{y}$. Additional radiolysis exposures are planned for the near-term future.
\end{abstract}





\section{INTRODUCTION}

A laboratory corrosion assessment of candidate materials for use in the SHINE process to produce ${ }^{99}$ Mo was initiated in 2014. The initial study [1] included a literature review and subsequently examined static immersion of specimens in solution as well as in the vapor above the solution as a function of the exposure temperature and a wide range of solution chemistry. Supporting visual observations of the postexposure coupon condition, weight changes were used to estimate likely corrosion rates associated with each material/environment combination. In addition to standard coupons, a variety of galvanic couples between stainless steel alloys and zirconium-based materials were also examined, and limited cavitation testing was incorporated to consider a potential aspect of fluid velocity effects. Only very stable passivity, no changes in surface roughness, and near immeasurably low annualized corrosion rates were observed for all alloys and conditions examined.

As follow-up activity, the second year of effort - the results of which are documented in this reportfocused on two particular aspects of corrosion. The stress-corrosion cracking (SCC) susceptibility of candidate alloys was examined using both standard U-bend test specimens as well as slow-strain rate mechanical testing in many of the same solutions as previously examined [1]. In addition, electrochemical polarization testing was used to assess and compare passive film stability and corrosion characteristics as a function of fluid velocity spanning the range of stagnant ( zero velocity) to several $\mathrm{m} / \mathrm{s}$ (visually turbulent characteristics). Limited additional vibratory horn testing was performed to examine potential cavitation characteristics for uranium-bearing solutions compared to similar solutions with the uranium component removed. Finally, initial testing at the Gamma Irradiation Facility (GIF) at the High Flux Isotope Reactor (HFIR) to examine the potential effects of radiolysis was conducted.

\section{EXPERIMENTAL PROCEDURE}

\subsection{STRESS-CORROSION CRACKING WITH U-BENDS}

The general guidance of ASTM G30 [2] was followed in the preparation and exposure of U-bends in this investigation. Specimens for bend testing were prepared from flat rectangular stock machined to the dimensions indicated in Figure 1. The flat stock was ground to an average surface roughness of $<1 \mu \mathrm{m}$ (about $16 \mathrm{rms}$ ). Following initial degreasing in ethanol, the specimens were then bent into the desired "U" shape using the two-stage method. In this method, each specimen was bent partially toward the U-shaped configuration ("legs" of the U not quite parallel) using a fixture designed to deliver a $12.5 \mathrm{~mm}$ (0.5 in.) bend radius. Just prior to exposure to the test environment of interest, the specimen was cleaned with acetone, weighed, and bent into the final/complete U-shape. The final bending was accomplished with the aid of a vise holding the open end of the U-shape at the proper dimension (inside surfaces of the "legs" of the U-shape separated by $25 \mathrm{~mm}$ ) while the stainless steel bolting and Teflon shoulder washers were put in place and tightened. The purpose of the Teflon shoulder washers was to eliminate any dissimilar metal contact between the stainless steel bolting material and the U-bend alloy of interest. In this fashion, the U-bend was prepared for exposure with no relaxation of the elastic portion of the bending stress. 


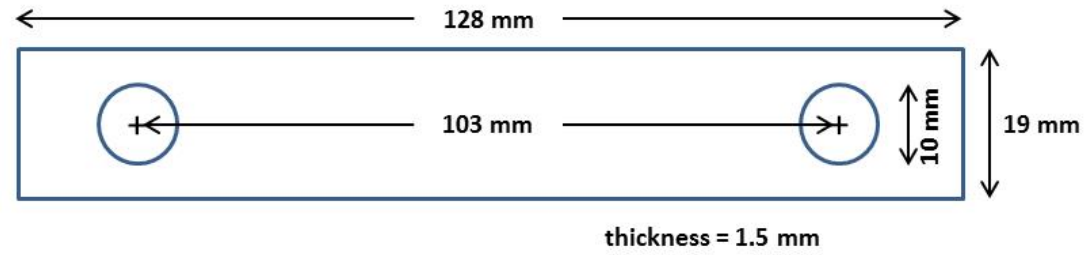

Figure 1. Dimensions of flat stock panels used to generate $\mathbf{U}$-bend specimens. The holes for the bolting hardware are centered in both the longitudinal and transverse directions. These dimensions correspond roughly with $5 \times 3 / 4 \times 1 / 16$ in.

Following completion of the bending procedure, the fully assembled specimens (Figure 2) were placed within standard $1 \mathrm{~L}$ Erlenmeyer flasks for exposure. The flasks were fitted with a cold finger condenser (cooling water kept $<30^{\circ} \mathrm{C}$ by a recirculation unit) supported by a Kalrez o-ring to eliminate evaporation and vapor escape from the flask. The o-rings also served to keep droplets of moisture condensation on the top of the cold finger surface from trickling down the condenser surface and entering the test solution (thus avoiding dilution from this source).

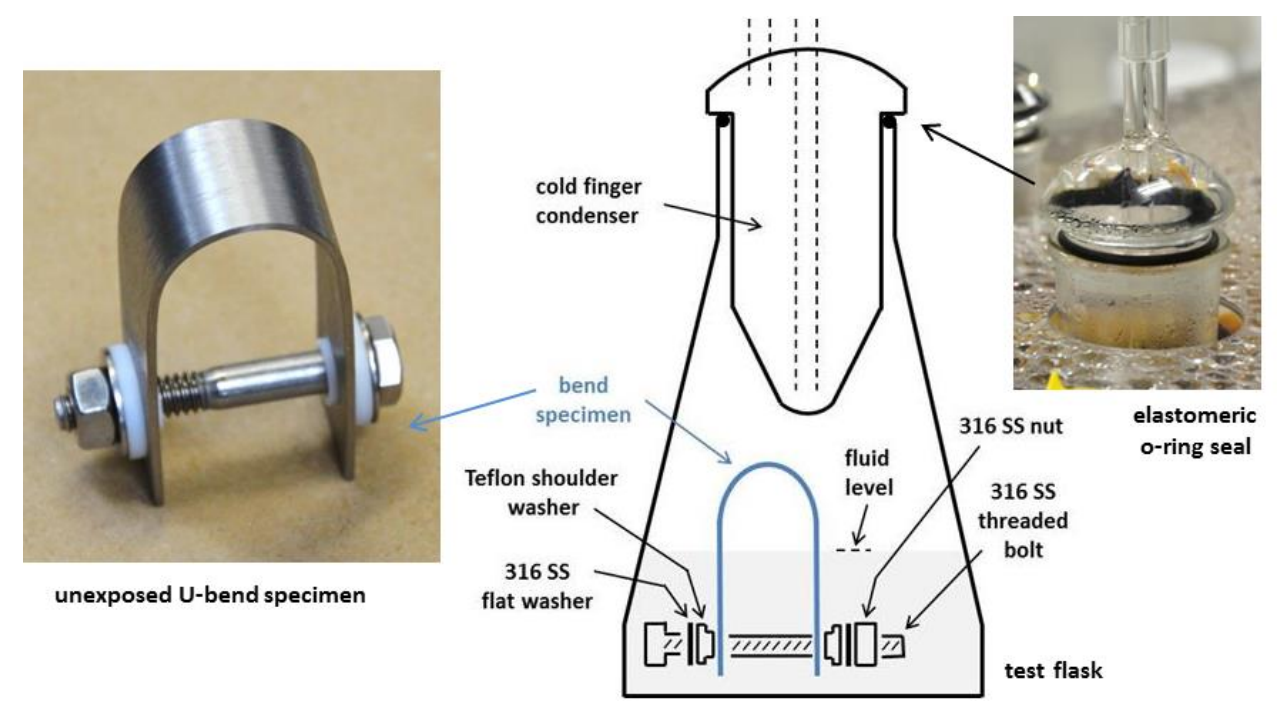

Figure 2. U-bend test arrangement. The fully formed U-bend specimen (left) is placed within the flask containing the test solution and the flask fitted with a cold-finger condenser supported by an o-ring.

Typically, each flask contained $300 \mathrm{ml}$ of the test solution of interest, and up to four flasks were placed together within a constant temperature bath filled with water. After the flasks were in place within the constant temperature bath, hollow plastic beads (about $1.5 \mathrm{~cm}$ diameter) were added to the bath surface to a depth of about 8-10 $\mathrm{cm}$ to retard evaporation of water from the bath. Further, for the same purpose, a thin plastic lid (with holes through which each flask neck could extend) was placed over the entire bath.

For each experiment, the test solutions of interest were brought to within a few degrees of the desired temperature prior to placing the U-bend specimens within each flask. The U-bends-lowered into each flask with long-fingered stainless steel tongs-were exposed primarily in two orientations: (1) a "standing" position (depicted in Figure 2), such that the bend apex of the specimen was exposed to the vapor above the solution of interest, and (2) a horizontal position, such that the entire U-bend was fully immersed within the test solution. In a very limited number of cases, the amount of solution within the vessel was reduced such that the U-bend could be positioned in a horizontal orientation with the solution line intersecting the bend apex. The surface area of the entire (bare) U-bend is about $52 \mathrm{~cm}^{2}$, although the shoulder washer partially covers (and thereby potentially protects) a small portion of the surface. When 
exposed in the standing orientation, about $20 \mathrm{~cm}^{2}$ is exposed to vapor only. As a result of uncertainties in the total area exposed and in recognition of the possibility that different regions-immersed, vapor, and liquid/vapor interface - on each specimen are likely corroding at different rates, it should be recognized that corrosion rate calculations generated from weight change are ultimately only rough approximations of the specific rate averaged over the entire specimen surface.

The U-bends were exposed within their respective solutions initially for 10 days at $80-81^{\circ} \mathrm{C}$. Following the initial exposure, the still fully assembled U-bends were removed from solution and lightly cleaned (ultrasonic soak in water, rinse with acetone) to facilitate observation of the bend area (and the rest of the specimen), looking for signs of cracking or surface roughening. Subsequently, undamaged U-bends were returned to the same flasks from which they were removed (solution chemistry unchanged; specimen orientation retained) for 10 additional days of exposure with the solution temperature raised to $93-94^{\circ} \mathrm{C}$. Following the complete 20 day exposure, the cleaning process was repeated, and specimens were again observed for cracks. The U-bends were then disassembled, the cleaning process repeated, and then the original U-bend specimen reweighed. In selected (limited) cases, routine visual assessment of the U-bends (strong light, 15× lens) was supported with dye-penetrant examination and/or metallographic examination.

Consistent with the previous effort [1] for this experimental program, U-bends of four candidate stainless steel alloys were included in the U-bend testing: austenitic types 304L, 316L, and 17-4 PH and duplex type 2304. Each was examined in the mill-annealed (solution treated) condition. The composition of each material is given in Table 1.

Table 1. Composition (wt. \%) for stainless steel specimens subjected to U-bend testing. Data taken from mill certification provided by the supplier

\begin{tabular}{ccccc}
\hline & \multicolumn{4}{c}{ Test material } \\
\cline { 2 - 5 } Element & 304L & 316L & $\mathbf{2 3 0 4}$ & $\mathbf{1 7 - 4 ~ P H}$ \\
\hline $\mathrm{Cr}$ & 18.08 & 16.80 & 23.05 & 15.28 \\
$\mathrm{Ni}$ & 8.02 & 10.00 & 4.2 & 4.22 \\
$\mathrm{Mo}$ & 0.36 & 2.01 & 0.13 & 0.14 \\
$\mathrm{Mn}$ & 1.62 & 1.15 & 1.84 & 0.54 \\
$\mathrm{Si}$ & 0.34 & 0.45 & 0.52 & 0.41 \\
$\mathrm{Cu}$ & 0.47 & 0.43 & - & 3.41 \\
$\mathrm{C}$ & 0.025 & 0.023 & 0.02 & 0.04 \\
$\mathrm{~N}$ & 0.064 & 0.053 & 0.12 & - \\
$\mathrm{P}$ & 0.030 & 0.029 & 0.027 & 0.024 \\
$\mathrm{Si}$ & 0.003 & 0.002 & 0.001 & 0.004 \\
$\mathrm{Co}$ & - & - & 0.077 & - \\
$\mathrm{Nb}$ & - & - & - & 0.31 \\
$\mathrm{Fe}$ & balance & balance & balance & balance \\
\hline
\end{tabular}

Also consistent with the previous effort [1] on this experimental program, Zr-4 and a Zr-2.5Nb alloy were also included in the U-bend testing. U-bend specimens of these alloys were machined from $19 \mathrm{~mm}$ thick plate with the composition given in Table 2. 
Table 2. Composition (wt. \%) for zirconium-based alloys. Data taken from the mill certification for the original ingots. No other elements were detected in concentrations above $30 \mathrm{wppm}$

\begin{tabular}{ccc}
\hline & \multicolumn{2}{c}{ Zirconium-based alloy } \\
\cline { 2 - 3 } Element & Zr-4 & Zr-2.5Nb \\
\hline $\mathrm{Zr}$ & balance & balance \\
$\mathrm{Cr}$ & 0.11 & - \\
$\mathrm{Fe}$ & 0.20 & 0.10 \\
$\mathrm{Sn}$ & 1.52 & - \\
$\mathrm{Nb}$ & - & 2.58 \\
$\mathrm{O}$ & 0.15 & 0.09 \\
$\mathrm{C}$ & 0.014 & - \\
\hline
\end{tabular}

Unlike the stainless steel U-bends, which remained bright and shiny following machining and assembly, the as-machined zirconium alloys exhibited a dull brown oxide. The oxide likely formed as a result of modest heating in air generated by the final milling process. This oxide was quite thin and adherent and was not obviously distressed (cracked, spalled) during the process to complete the U-bend assembly. Some zirconium alloy specimens were exposed to the various test solutions in this condition (machining oxide retained), while others were first pickled to remove the oxide prior to exposure in the same test solutions. The pickling procedure (modeled roughly after ASTM B614 [3]) used a solution of $25 \mathrm{ml}$ reagent-grade nitric acid, $3.5 \mathrm{ml}$ reagent-grade hydrofluoric acid, with distilled water to $100 \mathrm{ml}$ total. Following the first stage of bending, oxidized zirconium specimens were ultrasonically soaked in this solution at room temperature for 3-5 minutes. Following similar ultrasonic cleaning in water and acetone, the bending procedure was completed and bolting applied. Figure 3 compares the appearance of the asmachined oxidized surface and a similar pickled specimen of Zr-4 prior to testing.

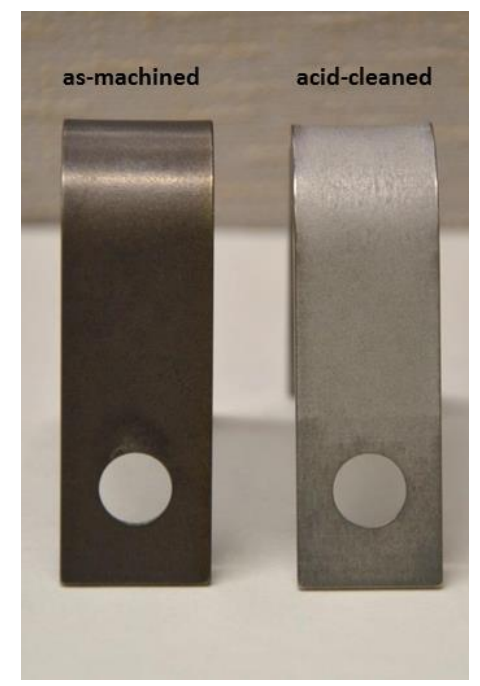

Figure 3. As-machined (left) and pickled (right) specimens of Zr-4 prior to test exposure.

To prepare baseline solutions for testing, reagent-grade depleted uranyl sulfate trihydrate $\left(\mathrm{UO}_{2} \mathrm{SO}_{4} \bullet 3 \mathrm{H}_{2} \mathrm{O}\right)$ was purchased from a commercial supplier in coarse powder form and added to reagent-grade water in appropriate amounts. The certificate accompanying the trihydrate material claimed $99.9 \%$ purity, with a total insoluble matter content of $<0.005 \%$. Chlorides, iron, and heavy metals (as lead) were all reported as $<0.002 \%$, and other sulfates (alkali metals and alkali earths) at less than $0.05 \%$. At $420.1 \mathrm{~g} / \mathrm{mol}$ for the trihydrate, the uranium fraction of this material was about 56.7\%; thus, for example, $246.9 \mathrm{~g}$ of trihydrate 
per liter of water was required to achieve $140 \mathrm{~g}$ dU/L, which was a common concentration used in these tests. The sulfate was readily soluble in room temperature water across the entire range of solute concentrations selected, generating a bright yellow solution and a slight volume increase ( 40-100 ml per liter, depending on concentration) resulting from the solid addition. In addition to variable uranium concentration, test solutions also incorporated variable excess sulfuric acid, iodine content (as KI and $\mathrm{KIO}_{3}$ ), and nitric acid to consider different electrochemical potentials and potential halide contamination generated as a fission product. Other details of solution selection and preparation have been reported previously [1].

Stainless steel U-bend specimens of each alloy were exposed—standing and horizontal orientations - to all except one of the solutions listed in Table 3, while zirconium alloys-with and without the asmachined oxide film - were exposed in standing and horizontal orientation to a smaller subset of these solutions.

Table 3. Alloy/environment combinations for the U-bend stress corrosion cracking tests

\begin{tabular}{lcl}
\hline \multicolumn{1}{c}{ Alloys tested } & \multicolumn{1}{c}{ Test environments } \\
\hline $\begin{array}{l}\text { stainless } \\
\text { stainless } \\
\text { stainless }\end{array}$ & $\mathrm{Zr}$ & $\begin{array}{l}140 \mathrm{~g} \mathrm{dU} / \mathrm{L}+0.1 \mathrm{M} \text { excess sulfuric acid } \\
140 \mathrm{~g} \mathrm{dU} / \mathrm{L}+0.1 \mathrm{M} \text { excess sulfuric acid }+10 \mathrm{wppm} \text { iodine } \\
140 \mathrm{~g} \mathrm{dU} / \mathrm{L}+0.1 \mathrm{M} \text { excess sulfuric acid }+25 \mathrm{wppm} \text { iodine }\end{array}$ \\
\hline stainless & $\mathrm{Zr}$ & $140 \mathrm{~g} \mathrm{dU} / \mathrm{L}+1.0 \mathrm{M}$ excess sulfuric acid + $10 \mathrm{wppm}$ iodine \\
\hline $\begin{array}{l}\text { stainless } \\
\text { stainless }\end{array}$ & & $\begin{array}{l}140 \mathrm{~g} \mathrm{dU} / \mathrm{L}+0.25 \mathrm{M} \text { excess nitric acid } \\
140 \mathrm{~g} \mathrm{dU} / \mathrm{L}+0.25 \mathrm{M} \text { excess nitric acid }+10 \text { wppm iodine }\end{array}$ \\
\hline $\begin{array}{l}\text { stainless } \\
\text { stainless }\end{array}$ & $\mathrm{Zr}$ & $70 \mathrm{~g} \mathrm{dU} / \mathrm{L}+0.1 \mathrm{M}$ excess sulfuric acid $+10 \mathrm{wppm}$ iodine \\
\hline & & $70 \mathrm{~g} \mathrm{dU} / \mathrm{L}+1.0 \mathrm{M}$ excess sulfuric acid $+10 \mathrm{wppm}$ iodine \\
\hline
\end{tabular}

\subsection{STRESS-CORROSION CRACKING WITH SLOW-STRAIN RATE TENSILE TESTS}

In contrast to the U-bend style examination for SCC susceptibility, which is a static strain test, the slowstrain rate (SSR) test incorporates a dynamic strain. As a result, the passive film on the specimen surface for an SSR test is constantly challenged in terms of fracture and reformation.

Figure 4 shows the test cell arrangement for the SSR experiments. The test vessel was fabricated using 316L stainless steel and was machined from a solid block to eliminate the need for welds and the associated quality control. To satisfy potential safety concerns associated with containment of a radioactive solution, the vessel incorporated a very heavy wall thickness despite the known compatibility of 316L and acidic uranyl sulfate solutions [1]. The tensile specimens were about $65 \mathrm{~mm}$ long with a test section (gage length) $20 \mathrm{~mm}$ long and $3.8 \mathrm{~mm}$ diameter. For each exposure, the specimen was threaded into the bottom of the container, and $50 \mathrm{ml}$ of the test solution of interest was added such that the test section was completely immersed. The container was then sealed, and four Kalrez o-rings at strategic positions prohibited any splash/spill losses or evaporation while permitting linear motion of the pull rod. 

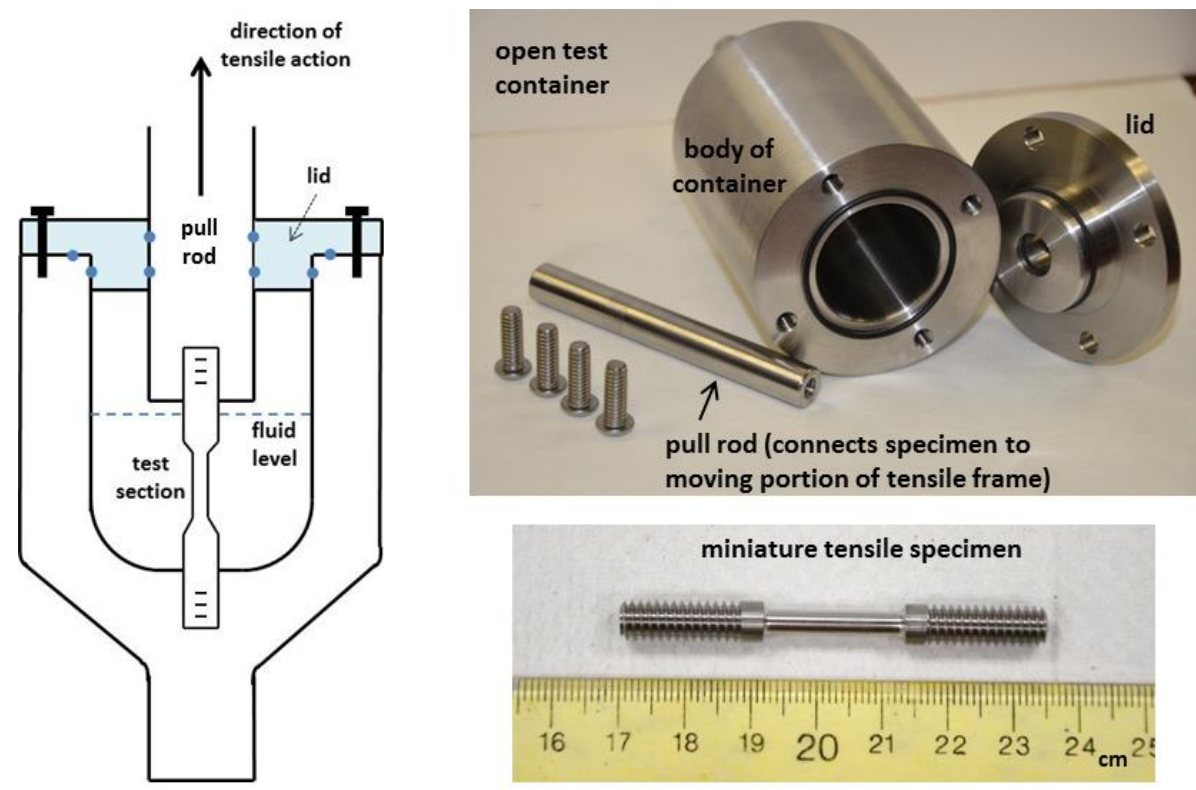

Figure 4. Schematic test cell with photographs of the test cell components and a miniature tensile specimen used for the slow-strain rate tests.

SSR tests were conducted at ambient temperature on each of five alloys-316L, 2304, 17-4 PH, Zr-4, and $\mathrm{Zr}-2.5 \mathrm{Nb}$ - at $0.51 \mathrm{~mm} / \mathrm{h}(0.020 \mathrm{in} . / \mathrm{h})$ constant extension rate resulting in exposures requiring $10-20 \mathrm{~h}$ to completely fracture the specimen. Typically, all five alloys in this test matrix were exposed in the same solution as opposed to generating a fresh solution for each SSR experiment. The solutions for SSR tests were prepared with distilled water and reagent-grade depleted uranyl sulfate as previously discussed, and the matrix of test solutions included

- distilled water,

- $140 \mathrm{~g} \mathrm{dU} / \mathrm{L}+0.1 \mathrm{M}$ excess sulfuric acid,

- $140 \mathrm{~g} \mathrm{dU} / \mathrm{L}+0.1 \mathrm{M}$ excess sulfuric acid + 25 wppm iodine,

- $140 \mathrm{~g} \mathrm{dU} / \mathrm{L}+1.0 \mathrm{M}$ excess sulfuric acid, and

- $140 \mathrm{~g} \mathrm{dU} / \mathrm{L}+0.25 \mathrm{M}$ excess nitric acid.

Following fracture, each specimen was cleaned (ultrasonic exposure in distilled water, rinsed in acetone) and the fracture surface of select specimens was examined in the scanning electron microscope.

Mechanical property test details-for example, ultimate tensile strength and ductility determined from the SSR stress-strain curve-and fracture face features resulting from exposure to distilled water (benign or inert in terms of SCC susceptibility for each alloy) were compared with the corresponding results developed during exposure to the prototypic environments to examine sensitivity to SCC for each alloy/environment combination.

\subsection{ELECTROCHEMICAL POLARIZATION AND FLUID VELOCITY}

Standard electrochemical polarization tests were performed on small disk-shaped specimens of the four different stainless steel alloys and the two zirconium-based alloys. The composition of the stainless steel specimens was the same as that for the flat panels previously examined [1], which is very similar (but not identical) to the compositions listed in Table 1, while the zirconium alloys were as listed in Table 2. The disk-shaped specimens, $11.2 \mathrm{~mm}$ in diameter and about $5 \mathrm{~mm}$ thick, were mechanically (tightly) press-fit into one open end of a non-conducting cylindrical hard-plastic sleeve (about $25 \mathrm{~mm}$ tall). These sleeves fixed the exposed area of the metallic specimen at precisely $1.0 \mathrm{~cm}^{2}$ and, within the inside diameter of the 
sleeve, provided for electrical connections from the specimen to the polarization equipment free from contact with the test solution. No indication—visually or in the resulting polarization scans—of crevice corrosion was observed between the specimen and the plastic sleeve at the press-fit contact area on any test.

Each specimen was carefully polished through $1 \mu \mathrm{m}$ alumina paste, washed in water, and finally rinsed in acetone immediately prior to placement in the plastic sleeve and submersion in the test solution. The reference electrode (saturated silver/silver chloride) and counter electrode (coil of platinum wire) were also immersed in solution in close proximity $(<25 \mathrm{~mm})$ to the working electrode surface. After immersion for about an hour to allow the specimen to achieve an approximately stable steady-state open circuit potential (OCP), the potential scan was initiated at $100 \mathrm{mV}$ less than OCP and scanned in a positive (anodic) direction at a rate of $10 \mathrm{mV} / \mathrm{min}$. Scans were discontinued when the potential reached $1000 \mathrm{mV}$ positive to OCP or a current threshold was passed.

Scans for each alloy were performed in the static solution that was saturated in oxygen (resulting from extended time in which the solution was exposed — unprotected — to the lab atmosphere). Two test solutions were examined in detail: the "baseline" solution of $140 \mathrm{~g} \mathrm{dU} / \mathrm{L}$ (as uranyl sulfate) with $0.1 \mathrm{M}$ added sulfuric acid and the same solution with 10 wppm iodine species (half as $\mathrm{KI}$ and half as $\mathrm{KIO}_{3}$ ) added just prior to testing. Most tests were performed at ambient temperature, but a limited number of polarization tests were performed at $50^{\circ} \mathrm{C}$ using jacketed glassware and a recirculating temperature bath. In addition to the static scans (no fluid velocity), scans in these solutions and at each temperature were also performed at various rotational speeds of the plastic sleeve cylinder to examine the effects of fluid velocity on polarization characteristics. Rotational speeds of 900, 1600, 2500, 3600, and 4900 rpm were examined for most specimen/environment combinations, corresponding to fluid velocity across the specimen surface of up to approximately 2.5 to $3.0 \mathrm{~m} / \mathrm{s}$, based on estimates from fluid dynamics calculations [4]. Figure 5 shows the polarization test cell and a specimen pressed within the sleeve-style holder, and Figure 6 is a schematic representation of a rotating specimen in solution.

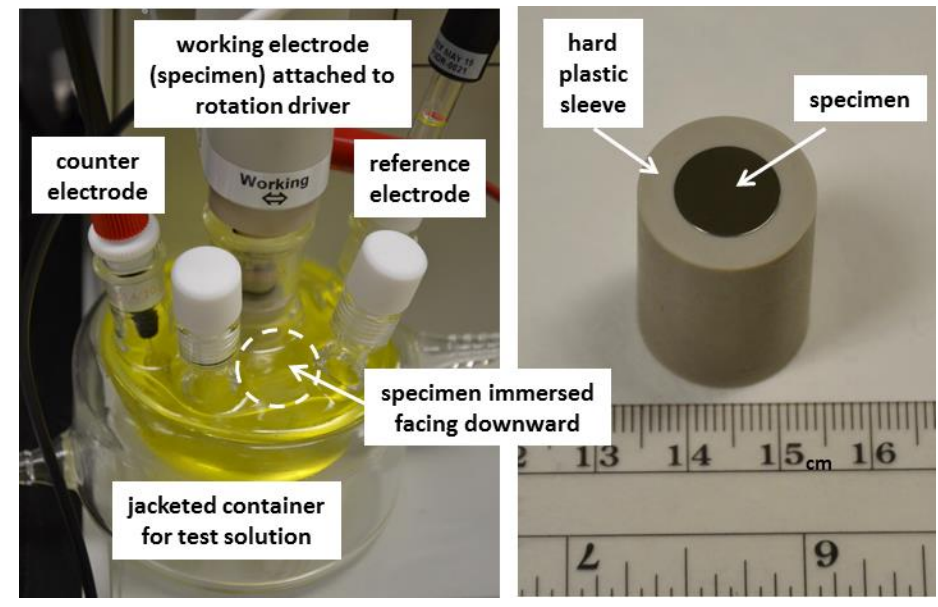

Figure 5. Electrochemical test cell containing depleted uranyl sulfate solution (yellow) along with a close-up of the rotating disk specimen. 


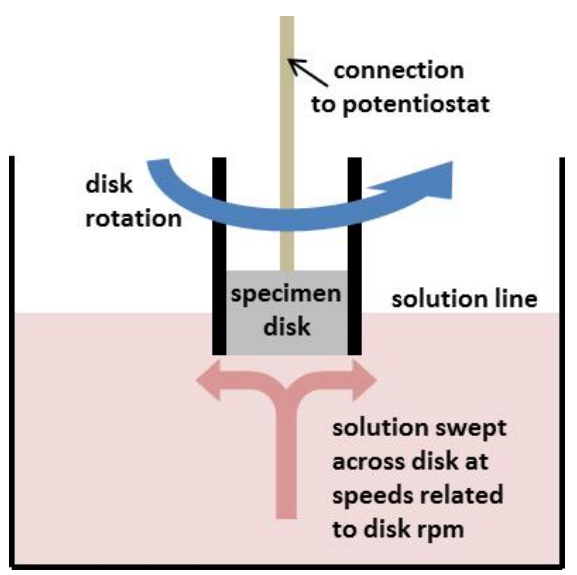

Figure 6. Schematic representation of the rotating disk electrode arrangement and the fluid motion generated as a function of rotational speed.

\subsubsection{Vibratory horn}

Although fluid velocities and flow conditions sufficient to generate erosion-corrosion conditions and/or cavitation are not expected in the SHINE process, limited experiments were performed to consider the relative impact of dissolved uranyl sulfate compared to similar density and $\mathrm{pH}$ solutions without uranyl sulfate. As a result, cavitation testing using a vibratory horn (meeting the intent of the protocol described in ASTM G32 [5]) was incorporated into the test plan. The test apparatus and protocol were described previously (ref. 1; testing was initiated in FY 2014), but key details are repeated here for the convenience of the reader.

Figure 7 shows the key components of the vibratory horn (fabricated using titanium) and a schematic diagram of a test specimen that mounts to the tip of the horn. Each vibratory horn is tuned for a specific specimen weight range (which for this size horn is $\sim 5-8 \mathrm{~g}$ ). Thus, to account for different densities among the various test materials, the dimension "h" shown in Figure 7 is varied to maintain a nearconstant mass for each test specimen.

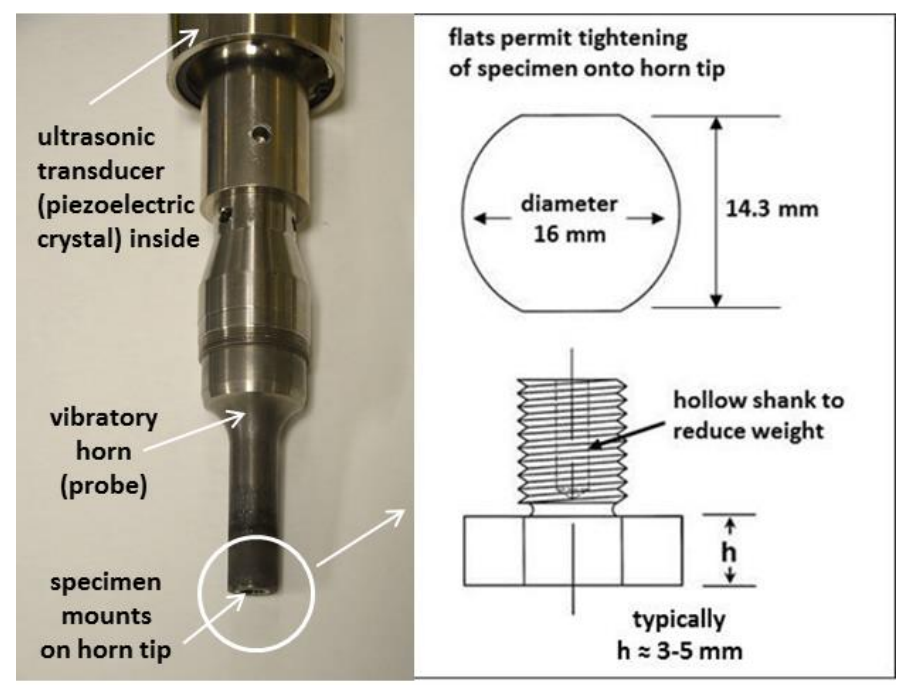

Figure 7. Key components of a vibratory horn (left) and details of a cavitation test specimen (right). 
Specimens were mounted on the tip of the vibratory horn and partially immersed (about $2 \mathrm{~mm}$ ) into the test solution of interest. In this case, the test fluid container was a jacketed glass vessel which permitted temperature control of the test solution via circulation of water from a constant temperature bath and maintained at $23^{\circ} \mathrm{C}$ in the present testing. Each test specimen had a surface area of $180 \mathrm{~mm}^{2}$ exposed to cavitation conditions (the flat surface perpendicular to the major horn axis). In all cases, the horn tip oscillated at a fixed frequency of $20 \mathrm{kHz}$ and was set to generate a peak-to-peak vibrational amplitude of $25 \mu \mathrm{m}$. The rapid reciprocating displacement of the specimen surface at the horn tip induces the formation and collapse of cavities in the liquid near the specimen surface, and damage can be quantified and compared via weight loss or, in sufficiently aggressive cases, pit depth. Each exposure in the present testing included $10 \mathrm{~s}$ of sonication followed by a pause of $10 \mathrm{~s}$ to permit corrosion or (re)passivation to occur after disruption of the normally passive film.

At $1 \mathrm{~h}$ intervals (30 minutes "on" and 30 minutes "off” of sonication), specimens were ultrasonically cleaned sequentially in distilled water and acetone, with each process followed by light wiping with a fresh paper towel. Mass change and observations of the test surfaces as a function of sonication time were recorded.

In previous testing, results were presented for exposures of the candidate alloys in (1) a test solution containing $140 \mathrm{~g}$ dU/L (made with depleted uranyl sulfate trihydrate) with $0.1 \mathrm{M}$ excess sulfuric acid added and (2) a solution prepared with acidified sodium sulfate $\left(\mathrm{Na}_{2} \mathrm{SO}_{4}\right)$ instead of uranyl sulfate to eliminate the uranium component of the solution. In the present extension of that testing, $140 \mathrm{~g} d \mathrm{~d} / \mathrm{L}$ with $1 \mathrm{M}$ sulfuric acid added was compared to a solution with a similar density and $\mathrm{pH}$ prepared with $\mathrm{Na}_{2} \mathrm{SO}_{4}$ and sulfuric acid.

\subsubsection{Irradiation test conditions}

Water is decomposed by high-energy radiation to yield predominantly hydrogen, oxygen, and hydrogen peroxide as well as perhaps several radicals formed from these constituents, and such radiolytic activity is expected within the SHINE process solution. While it was not practical to attempt precise duplication of the energy level(s) and fluence(s) associated with the expected SHINE process, it was possible to examine exposures that incorporate a radiolysis component. To do so, small corrosion test containers were prepared for exposure in the spent fuel pool at the High Flux Isotope Reactor (HFIR) in an area designed specifically for material assessments termed the Gamma Irradiation Facility (GIF). A portion of the container and specimen insert are shown in Figure 8 (additional details in ref. 1). The container and specimen "tree" are 316L stainless steel, and to satisfy safety regulations, the container wall is somewhat "over-designed" at $6.5 \mathrm{~mm}$ thick. 

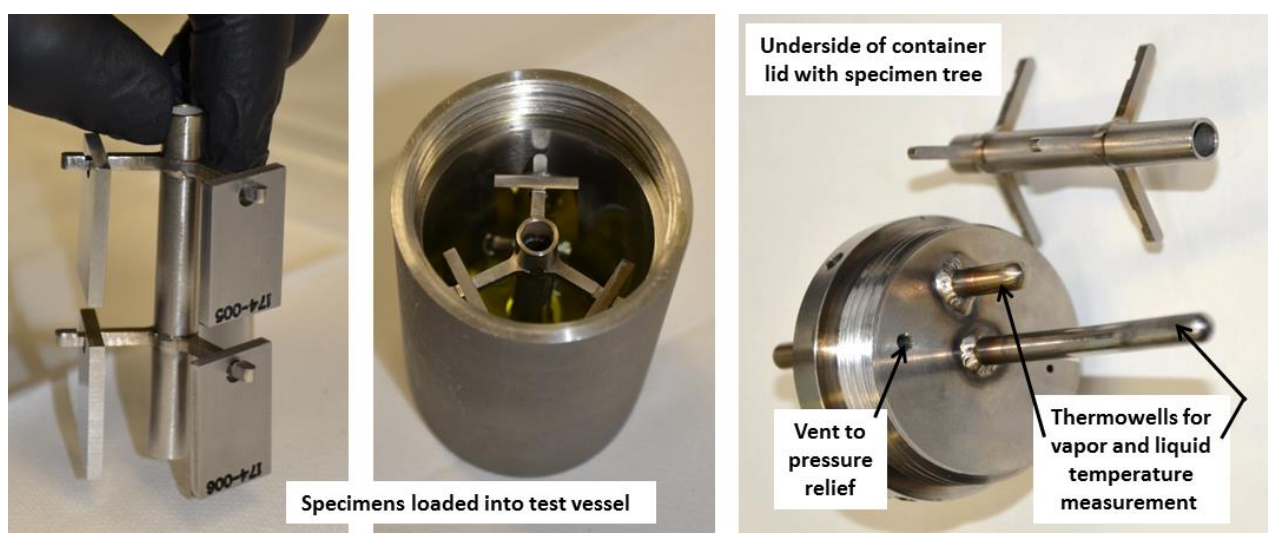

Figure 8. Views of the specimen "tree" and the HFIR/GIF test container vessel and lid. The approximate internal dimensions of the vessel are $5 \mathrm{~cm}$ diameter and $9 \mathrm{~cm}$ tall. The specimen tree slides over the thermowell that reaches the bottom of the container.

Each test container incorporated two thermowells attached to the vessel lid, one reaching almost to the bottom of the container and one reaching only a short distance from the lid, such that Type-K thermocouples could be used to monitor internal temperatures in the liquid and vapor, respectively. Each vessel lid was also fitted with two ports connected to the internal volume with redundant pressure-relief valves. These were required for safety considerations against the possibility of generating substantially more radiolytic hydrogen and oxygen than predicted by dosimetry estimates. While known not to have superior radiation resistance, a Kalrez ${ }^{\circledR}$ o-ring was also placed at the lid/container interface to ensure complete sealing against vapor loss. After assembly, the test containers were further enclosed within a certified over-pack canister that was inserted into the flux trap (central annulus) of a spent fuel assembly for exposure. Figure 9 shows a fully assembled test capsule (without the over-pack canister) and a mock flux trap to show the annular region into which the test containers with over-packs are positioned.

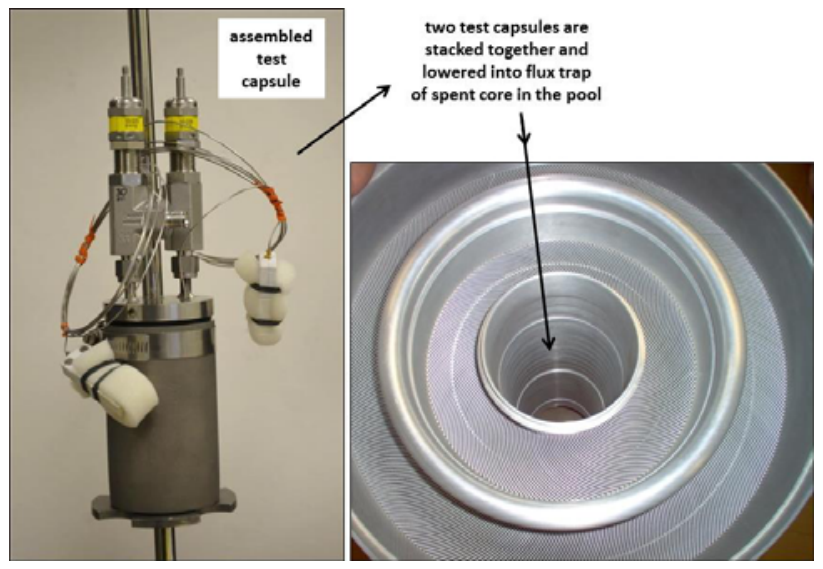

Figure 9. Fully assembled test capsule prior to placement within an over-pack (left) and a mock flux trap assembly.

The first several exposures in the HFIR/GIF facility were accomplished with a "blank" test containerthat is, only water (no specimens) in the container and a dosimetry package affixed to the external surface of the container. The purpose of these experiments was to select a suitable spent fuel assembly that generated a combination of appropriate internal temperature within the container (aiming for $60-70^{\circ} \mathrm{C}$ as prototypic to the SHINE process but safely remote to any tendency to boil) and a sufficiently high gamma flux intensity that a relatively short exposure (1-2 weeks) would generate the equivalent of many months or even years of exposure (equivalent dose) in the expected SHINE process. After several of these 
experiments, it was determined that very recently used, but perhaps not the freshest, spent fuel was necessary to achieve this combination.

In the initial exposure incorporating specimens and depleted uranyl sulfate solution described here, the fluid within the container represented the "baseline" solution of $140 \mathrm{~g}$ dU/L with $0.1 \mathrm{M}$ sulfuric acid added. About $60 \mathrm{ml}$ of solution within the container generated a fluid level appropriate to fully immerse the lower row of specimens on the holder, while the upper row of specimens remained exposed only in the vapor above the solution. Previous dosimetry indicated an expected equilibrium temperature of approximately $65^{\circ} \mathrm{C}$ and a gamma dose rate of $\sim 2 \mathrm{MRad} / \mathrm{h}$ for the selected core. Preliminary calculations for conditions expected within the SHINE vessel [6] suggest does rates of approximately 4-10 MRad/h neutron and 3-4 MRad/h gamma, indicating that the HFIR/GIF exposures produce a relevant dose for generating similar radiolysis conditions within the test fluid. Thus, while it is not possible to simulate SHINE conditions directly in these experiments (the ORNL/GIF exposure does not include neutron fluence), it is useful to compare corrosion rates for materials exposed to the same solutions with and without the radiolysis conditions to examine the magnitude of any potential changes.

Specimens for exposure were rectangles $30 \mathrm{~mm}$ in length, $19 \mathrm{~mm}$ wide, and $3 \mathrm{~mm}$ thick with a $4.5 \mathrm{~mm}$ hole centered near one end. Two test containers were stacked within the flux trap for exposure, placed roughly centered just above and just below the peak flux plane so that the exposures (gamma intensity and dose, temperature) in each container were essentially the same. One container included only stainless steel specimens (one each in liquid and in vapor), and the other container included both zirconium-based alloys and duplicates of the 316L specimens similarly exposed in the other container. An equilibrium temperature of $\sim 69^{\circ} \mathrm{C}$ was reached within an hour or so of insertion, and it decreased slightly (by $\sim 2^{\circ} \mathrm{C}$ ) over the week-long exposure. Figure 10 shows various views of the insertion of the test package into the spent fuel pool at HFIR/GIF.
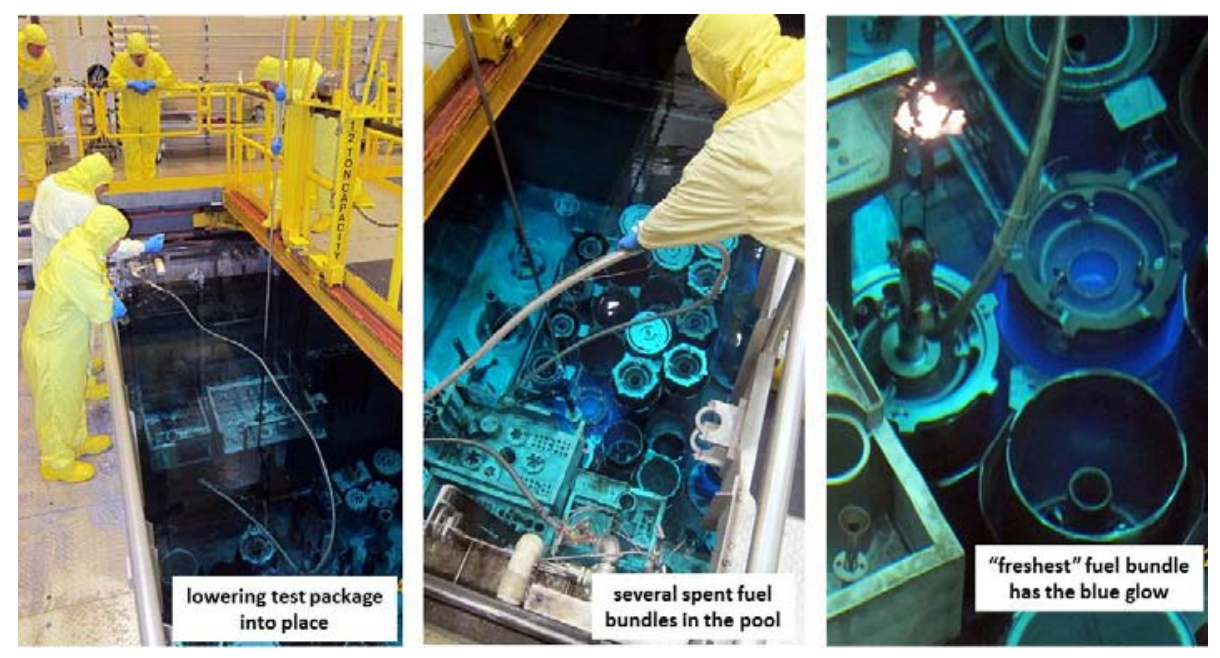

Figure 10. Views of the activity around the spent fuel pool at HFIR during placement of a corrosion test package within a flux trap.

\section{RESULTS AND DISCUSSION}

\subsection{STRESS-CORROSION CRACKING WITH U-BENDS}

Among all the different U-bend exposures, the most important result is that no evidence of cracking was observed on any of the specimens (stainless steel or zirconium-based alloys), general corrosion rates were very low and consistent with results from unstressed coupons previously reported [1], no increases in 
surface roughness or localized corrosion were observed as a result of exposure, and the discoloration patterns (resulting from minor oxidation) were as expected based on previous exposures. Further, no corrosion associated with the Teflon shoulder washers and the potential crevices they create was observed. Additional details of the results are described in the paragraphs that follow.

For U-bends positioned in the standing orientation, such that the bend apex was exposed above the solution line inside the flasks, modest accumulations of uranyl sulfate were frequently observed on the specimen surface just above the solution line. These accumulations were not particularly adherent, and the remnants that were not dislodged in routine handling were easily washed from the surface with distilled water. Further, no accelerated corrosion (e.g., surface roughening) was observed associated with the area beneath the accumulations, nor any change in the local discoloration characteristics of the specimen. Figure 11 is representative of this observation. Following cleaning (described in Section 2), and careful inspection for cracks with good lighting and a $15 \times$ lens, the U-bends were disassembled and the cleaning procedure repeated prior to reweighing the original sample.
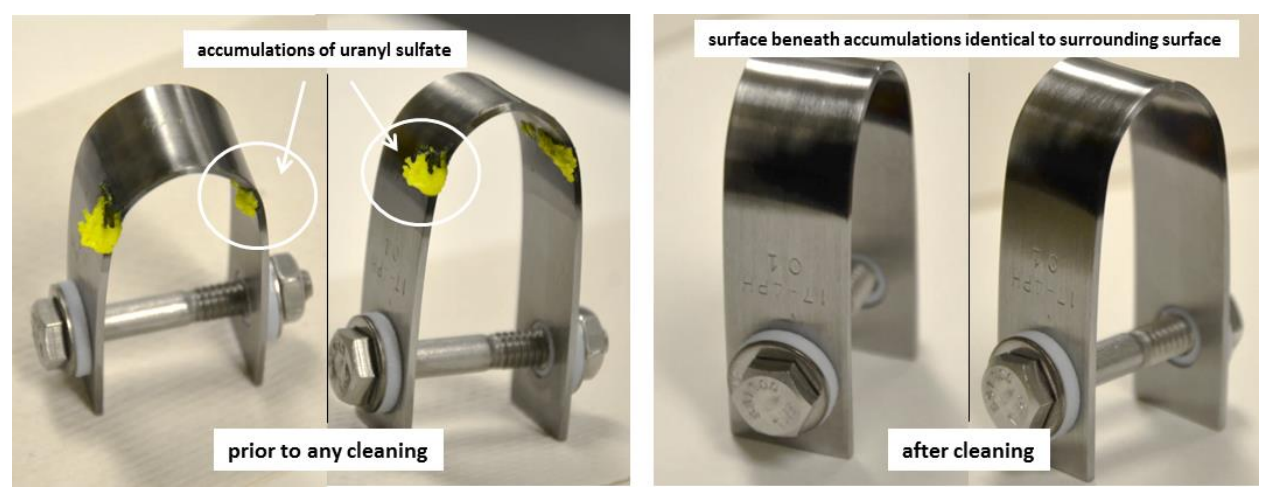

Figure 11. Representative U-bend specimen immediately upon removal from test flask (left) showing accumulations of depleted uranyl sulfate and the same specimen following cleaning (right).

Among the stainless steel U-bend specimens examined, the 17-4 PH alloys were often observed to be discolored to very dark gun blue or black as a result of exposure-predominantly on the immersed surfaces but not exclusively so-in patterns that were essentially identical to those observed on unstressed specimens that were previously evaluated [1]. The thickness of the dark film was not directly measured, but it appeared quite thin in that the original surface profile on the specimen surface remained readily visible and unchanged. Figure 12 shows a representative example of this observation, which compares the post-exposure appearance of 17-4 PH specimens with that of 2304 stainless steel in the same exposure environment. Note that in this comparison, the 2304 specimens appear essentially pristine compared to the 17-4 PH. The dark film on the 17-4 PH specimens-almost certainly an oxide but not analytically identified —was quite resistant to ultrasonic treatments in water and acetone and could not be wiped from the surface using paper towels. 


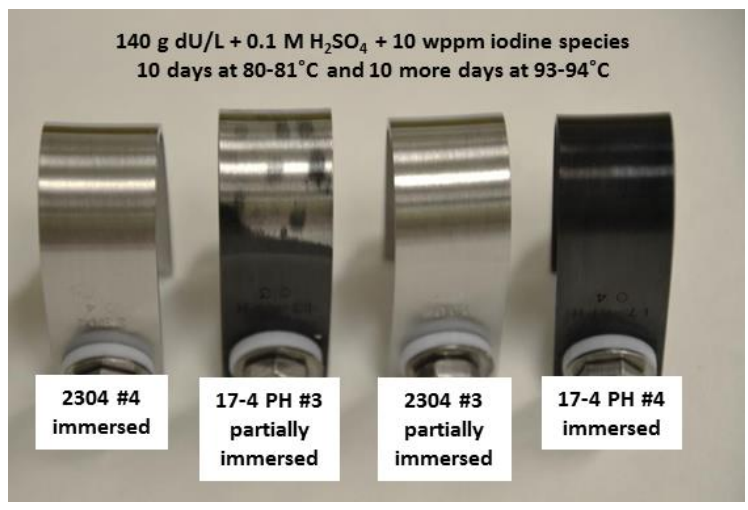

Figure 12. Post-exposure U-bends of 2304 and 17-4 PH stainless steels showing the contrast in coloration of the surface as a function of alloy type and specimen orientation during the exposure.

Only rarely were 304L, 316L, or 2304 observed to exhibit apparent discoloration at all in the U-bend exposures. This trend was also observed during exposures of the unstressed coupons [1], and in those rare cases a relatively subtle light golden brown was generally observed. Figure 13 shows an example of slight golden brown discoloration observed on type 316L specimens after an extended exposure. Among the limited U-bend exposures of stainless steels such that the bend apex was only partially immersed, the discoloration patterns were identical to those for fully immersed specimens.

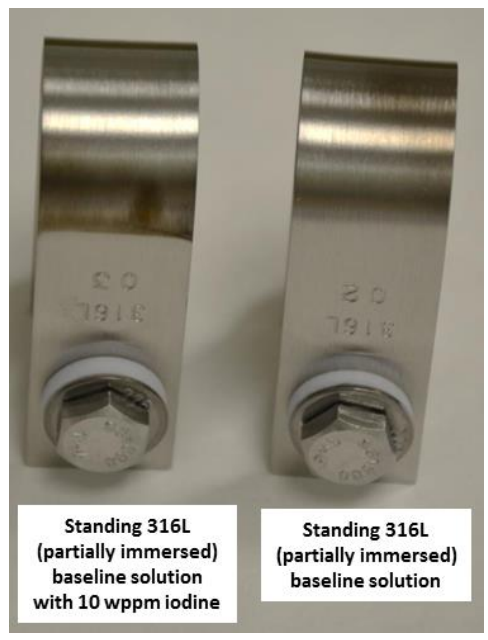

Figure 13. Post-exposure 316L stainless steel $\mathrm{U}$-bends showing light golden brown discoloration on the bend apex that was exposed above the solution line. Testing environments included the baseline solution (140 g dU/L +

$0.1 \mathrm{M}$ sulfuric acid) and the baseline solution with 10 wppm iodine species added. Both specimens exposed for 10 days at $80-81^{\circ} \mathrm{C}$ and 10 days at $93-94^{\circ} \mathrm{C}$.

The weight change associated with each cumulative exposure (10 days at $80-81^{\circ} \mathrm{C}$ and 10 more days at $93-94^{\circ} \mathrm{C}$ in each environment) was assessed for all alloy/environment combinations, but there are several factors that complicate the interpretation of that information and assignment of a corrosion rate derived from the weight change value. In the case of a very uniform post-exposure appearance and surface roughness for a fully immersed specimen, it seems reasonable use the total specimen area and total weight loss to assign a uniform corrosion rate to the entire specimen. However, for specimens which include both immersion and vapor space exposure and/or in which the post-exposure appearance of the specimen is not uniform, estimation of the corrosion rate applicable to the entire specimen or a specific portion of the specimen is problematic. For example, in the photograph of Figure 13, it is not clear what fraction of the total weight change should be assigned to the partially filmed region above the solution line, with further 
uncertainty generated by the fact that the relative degree of passivation associated with the film is unknown. In addition, the presence of the shoulder washers that partially cover and potentially shield from corrosion a small portion of the specimen area near the bolt holes may actually protect the metal (simply by excluding solution contact) or alternatively may locally accelerate corrosion (tendency to form a crevice at this location). However, in the experiments performed here, all the weight changes are sufficiently low and surface roughness sufficiently smooth/unchanged that the corrosion rates can be understood to be extremely low and of limited practical consequence, with results consistent with those generated for unstressed coupons and previously reported [1].

The total weight loss for each alloy/environment/orientation for the stainless steel U-bends is listed in Table 4. In recognition of the uncertainties described above, no attempt to assign a corrosion rate to the specimens based on the weight loss has been attempted. However, since the different stainless steels have comparable densities and each of the other factors associated with the corrosion rate calculation (time, total area) from weight loss are the same for each alloy, the weight loss values in Table 4 represent relative corrosion susceptibility comparisons. For example, the specimen weight losses suggest that the 17-4 PH alloy corrodes by a factor of about five to seven times more than the other stainless steels in most equivalent exposures. It is important to recognize that the highest weight loss suggested in Table 4 (0.02809 g, for the immersed 17-4 PH alloy in one of the nitric acid-bearing solutions) can be correlated, using specimen area, density, and time of exposure, to an average uniform corrosion rate of approximately $12 \mu \mathrm{m} / \mathrm{y}(0.5 \mathrm{mil} / \mathrm{y})$. Clearly, 17-4 PH corrosion rates for other exposure conditions are lower and span the range of perhaps $5-10 \mu \mathrm{m} / \mathrm{y}(0.2-0.4 \mathrm{mil} / \mathrm{y})$ as a generality.

The data in Table 4 also suggest a few other trends. For example, the weight losses (and analogous corrosion rates) are generally very comparable to each other (no meaningful differences in corrosion rate suggested) with uniform corrosion rates estimated to be on the order of 1-2 $\mu \mathrm{m} / \mathrm{y}$, with a high value of just less than $3 \mu \mathrm{m} / \mathrm{y}(0.1 \mathrm{mil} / \mathrm{y})$. No regular pattern associated with weight loss as a function of full immersion or only partial immersion was detected, suggesting that the vapor and liquid were similarly corrosive for these alloys and/or the exposure conditions encouraged the formation of a thin liquid film on surfaces apparently exposed in the vapor.

Table 4 also indicates the addition of iodine species to the test solution tends to have no significant effect on corrosion rate for all of these stainless steels in the baseline solution (compare the relative weight changes in the first three rows of each column in Table 4). At higher concentrations of sulfuric acid in combination with iodine additions (compare rows 2/4 with rows 7/8 in each column), 10 wppm iodine uniformly increases the weight loss (corrosion rate) of the stainless steels. The largest increase (the 304L standing specimen in $70 \mathrm{~g}$ dU/L solutions) is a factor of about three, but generally the increase is a factor of two or less. Note, too, that a 10 wppm iodine addition to the solution containing nitric acid uniformly increases the corrosion tendency for all the stainless steels, but the increase is quite small in all cases. Finally, recall [1] that the prototypic amount of iodine expected in the SHINE process is closer to 0.5 or $1 \mathrm{wppm}$, so that the data and trends indicated here regarding the presence of iodine perhaps exaggerate practical effects in the actual process.

Like the stainless steel specimens, none of the zirconium-alloy U-bends exhibited even a hint of cracking or any increase in surface roughness as a result of exposure. For specimens descaled prior to testing, discoloration was limited to development of light golden brown films (previously determined to be oxides [1]) that varied in relative darkness with the specific exposure environment. Figure 14 is an example of this observation for $\mathrm{Zr}-4$ alloys. For specimens not descaled prior to exposure, the resulting discoloration typically involved various shades of charcoal gray film that were only loosely adherent (based on contamination of the cleaning solutions and wipes, some of the film removed by the various cleaning steps). 
Table 4. Weight change (g) for stainless steel $\mathrm{U}$-bends exposed for a cumulative 20 days (10 days at $80-81^{\circ} \mathrm{C}$ and 10 days at $93-94^{\circ} \mathrm{C}$ ) in the indicated solutions and specimen orientations. Original weight of U-bend specimens was $\sim 25 \mathrm{~g}$ for each of 304L, 316L, and 17-4 PH and $\sim 30 \mathrm{~g}$ for 2304

\begin{tabular}{|c|c|c|c|c|c|c|c|c|}
\hline \multirow[b]{2}{*}{ Test environments } & \multicolumn{8}{|c|}{ Alloy and test orientation } \\
\hline & $\begin{array}{c}\text { Immersed } \\
316 \mathrm{~L}\end{array}$ & $\begin{array}{c}\text { Standing } \\
\text { 316L }\end{array}$ & $\begin{array}{c}\text { Immersed } \\
\text { 304L }\end{array}$ & $\begin{array}{l}\text { Standing } \\
\text { 304L }\end{array}$ & $\begin{array}{c}\text { Immersed } \\
2304\end{array}$ & $\begin{array}{c}\text { Standing } \\
2304\end{array}$ & $\begin{array}{c}\text { Immersed } \\
17-4 \mathrm{PH}\end{array}$ & $\begin{array}{c}\text { Standing } \\
\text { 17-4 PH }\end{array}$ \\
\hline $140 \mathrm{~g} \mathrm{dU} / \mathrm{L}+0.1 \mathrm{M}$ excess sulfuric acid & 0.00231 & 0.00200 & 0.00279 & 0.00242 & 0.00193 & 0.00237 & 0.01660 & 0.01761 \\
\hline $140 \mathrm{~g} \mathrm{dU} / \mathrm{L}+0.1 \mathrm{M}$ excess sulfuric acid + 10 wppm iodine & 0.00318 & 0.00306 & 0.00275 & 0.00240 & 0.00237 & 0.00234 & 0.02049 & 0.01551 \\
\hline $140 \mathrm{~g} \mathrm{dU} / \mathrm{L}+0.1 \mathrm{M}$ excess sulfuric acid +25 wppm iodine & 0.00329 & 0.00262 & 0.00274 & 0.00291 & 0.00228 & 0.00234 & 0.01523 & 0.01340 \\
\hline $140 \mathrm{~g} \mathrm{dU} / \mathrm{L}+1.0 \mathrm{M}$ excess sulfuric acid + 10 wppm iodine & 0.00414 & 0.00399 & 0.00405 & 0.00500 & 0.00285 & 0.00327 & 0.02261 & 0.02313 \\
\hline $140 \mathrm{~g} \mathrm{dU} / \mathrm{L}+0.25 \mathrm{M}$ excess nitric acid & 0.00303 & 0.00295 & 0.00242 & 0.00244 & 0.00171 & 0.00154 & 0.01956 & 0.01786 \\
\hline $140 \mathrm{~g} \mathrm{dU} / \mathrm{L}+0.25 \mathrm{M}$ excess nitric acid + 10 wppm iodine & 0.00384 & 0.00351 & 0.00398 & 0.00277 & 0.00274 & 0.00208 & 0.02809 & 0.01991 \\
\hline $70 \mathrm{~g} \mathrm{dU} / \mathrm{L}+0.1 \mathrm{M}$ excess sulfuric acid + 10 wppm iodine & 0.00246 & 0.00217 & 0.00219 & 0.00205 & 0.00159 & 0.00166 & 0.01544 & 0.01064 \\
\hline $70 \mathrm{~g} \mathrm{dU} / \mathrm{L}+1.0 \mathrm{M}$ excess sulfuric acid + 10 wppm iodine & 0.00440 & 0.00433 & 0.00405 & 0.00603 & 0.00311 & 0.00332 & 0.02350 & 0.01966 \\
\hline
\end{tabular}




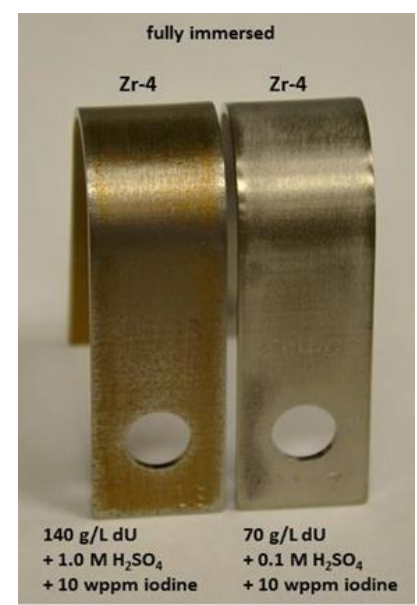

Figure 14. Post-exposure U-bends of $\mathrm{Zr}$-4 showing variable degrees of development of a golden brown film.

Weight change data was also collected for the zirconium-based alloy U-bends, and that information is summarized in Table 5. Several trends are highlighted by the comparative weight losses indicated. For example, there is no regular pattern of influence for uranium concentration in solution on the relative corrosion rates, as can be seen by comparing the results for rows 1, 2, and 3 in any column. However, it is apparent that testing of specimens with residual oxide on the surface yields a much higher weight loss than that for the equivalent experiment on the same alloy that was descaled prior to testing. Across all the different comparisons of that type in Table 5, the average increase of that type is about a factor of 40 (on a range of 6 to almost 150 across all experiments). It is suspected that essentially all of this difference in weight loss is related to the dissolution of the oxide formed during machining and the subsequent formation of the oxide most stable in aqueous solution.

An increase in the sulfuric acid concentration had very little effect on the $\mathrm{Zr}-4 \mathrm{U}$-bends, but the $\mathrm{Zr}-2.5 \mathrm{Nb}$ specimens exhibited increased weight loss with higher sulfuric acid concentration (compare rows 2 and 4). For nearly all pairs of standing/horizontally exposed specimens, the fully immersed (horizontal) specimen exhibited a slightly higher weight loss than the corresponding standing (partially immersed) specimen, suggesting the difference is related mostly to the amount of exposed area in solution. There are two minor exceptions to that trend for Zr-4, for the two lowest weight changes among the immersed Zr-4 specimens.

Again, similar to the case for the stainless steel U-bends, none of the corrosion rates suggested by the weight losses in Table 5 have practical significance. The highest corrosion rate associated with the descaled zirconium alloys (row 4; $\mathrm{Zr}-2.5 \mathrm{Nb}$ ) corresponds to a uniform general corrosion rate of about $4 \mu \mathrm{m} / \mathrm{y}$, with average values in the range of $1-2 \mu \mathrm{m} / \mathrm{y}$, similar to those observed for the stainless steels. Higher corrosion rates for the specimens that were not descaled potentially have more significance from a product purity point of view (potential entrainment of soluble corrosion products) than from a structural point of view, as most of the apparent increase in corrosion is related to the loss of the original unstable passive film. 
Table 5. Weight change (g) for zirconium alloy $U$-bends exposed for a cumulative 20 days $\left(10\right.$ days at $80-81^{\circ} \mathrm{C}$ and 10 days at $\left.93-94^{\circ} \mathrm{C}\right)$ in the indicated solutions and specimen orientations. Original weight of U-bend specimens was $\sim 23 \mathrm{~g}$ for each of $\mathrm{Zr}-4 \mathrm{and} \mathrm{Zr}-2.5 \mathrm{Nb}$

\begin{tabular}{|c|c|c|c|c|c|c|c|c|}
\hline \multirow{3}{*}{ Test environments } & \multicolumn{8}{|c|}{ Alloy, surface condition, and test orientation } \\
\hline & \multicolumn{4}{|c|}{ Pre-test descaling } & \multicolumn{4}{|c|}{ Retain as-machined oxide } \\
\hline & $\begin{array}{c}\text { Immersed } \\
\mathrm{Zr}-4 \\
\end{array}$ & $\begin{array}{c}\text { Standing } \\
\text { Zr-4 }\end{array}$ & $\begin{array}{c}\text { Immersed } \\
\mathrm{Zr}-2.5 \mathrm{Nb}\end{array}$ & $\begin{array}{l}\text { Standing } \\
\text { Zr-2.5Nb }\end{array}$ & $\begin{array}{c}\text { Immersed } \\
\mathrm{Zr}-4\end{array}$ & $\begin{array}{c}\text { Standing } \\
\text { Zr-4 }\end{array}$ & $\begin{array}{c}\text { Immersed } \\
\mathrm{Zr-2.5Nb}\end{array}$ & $\begin{array}{l}\text { Standing } \\
\text { Zr-2.5Nb }\end{array}$ \\
\hline $70 \mathrm{~g} \mathrm{dU} / \mathrm{L}+0.1 \mathrm{M}$ excess sulfuric acid + $10 \mathrm{wppm}$ iodine & 0.00178 & 0.00179 & 0.00299 & 0.00150 & 0.04702 & 0.03769 & 0.03861 & 0.03580 \\
\hline $140 \mathrm{~g} \mathrm{dU} / \mathrm{L}+0.1 \mathrm{M}$ excess sulfuric acid + 10 wppm iodine & 0.00162 & 0.00268 & 0.00318 & 0.00117 & & & & \\
\hline $280 \mathrm{~g} \mathrm{dU} / \mathrm{L}+0.1 \mathrm{M}$ excess sulfuric acid +10 wppm iodine & 0.00101 & 0.00044 & 0.00606 & 0.00137 & 0.06023 & 0.03728 & 0.04696 & 0.02981 \\
\hline $140 \mathrm{~g} \mathrm{dU} / \mathrm{L}+1.0 \mathrm{M}$ excess sulfuric acid + 10 wppm iodine & 0.00038 & 0.00222 & 0.00787 & 0.00273 & 0.05586 & 0.04932 & 0.04499 & 0.04010 \\
\hline
\end{tabular}




\subsection{STRESS-CORROSION CRACKING WITH SLOW-STRAIN RATE TENSILE TESTS}

In the dynamic SSR test, potential susceptibility to SCC is assessed by comparison of the typical stressstrain curves as well as the fracture characteristics for tensile specimens exposed to a relatively benign environment (e.g., water or argon) with identical specimens exposed in a prototypic environment in which the potential for SCC is less certain. Key qualitative indicators include relatively diminished specimen strength, elongation, and/or reduction in area in the potentially aggressive environment. Further, changes in the structural details on the fracture face as a function of exposure environment, such as presence and density of secondary cracks, cleavage-like features, and corrosion patterns can be detected using the scanning electron microscope (SEM).

The most important result for the SSR testing is that none of the alloys mechanically tested in prototypic environments revealed any change in fracture characteristics compared to identical specimens pulled to failure in water. Representative observations and details appear in the paragraphs that follow.

The key tensile test results for each material are summarized in Tables 6-10. The time required to fracture each specimen is recorded as a convenient test parameter, with the start time ( $\mathrm{t}=0$ seconds) being the time at which the load cell first indicates the "slack" has been removed from the system and further motion of the crossheads represents a positive tensile load (typically, > $10 \mathrm{lb}$ ) on the specimen. [Note that in the discussion that follows regarding the mechanical stress-strain curves and related data, all the measurements were collected in English units - that is, load recorded in pounds and extension recorded in inches - and it remains traditional to report the curves/data in that fashion. As a result, the figures and tables that contain this data also report English units. In some places in the discussion, relevant metric system units are also included.] Ultimately, the time to failure information is also included within the total fracture strain, as the constant extension rate of the test correlates directly to the length of the specimen gage length at failure. The maximum load achieved in each test is also reported as indicative of sensitivity to premature cracking and loss of load-bearing cross-sectional area. For each of the five materials examined, as is evident in Tables 6-10, these key values are insensitive to test environment within the potential scatter of the test method (a few percent), thus suggesting immunity of these materials to SCC under these exposure conditions. The largest "scatter" appears to be in the data for the 17-4 PH stainless steel (Table 8); in this case, the potentially more aggressive environments actually yield substantially larger time to failure and fracture strain than the test in water.

Table 6. Key parameters from the stress-strain curves for 316L stainless steel as a function of test environment

\begin{tabular}{lccccc}
\hline \multicolumn{1}{c}{ 316L } & Water & $\begin{array}{c}\text { Baseline } \\
\text { solution }\end{array}$ & $\begin{array}{c}\text { Baseline } \\
\text { w/iodine }\end{array}$ & $\begin{array}{c}\text { Baseline } \\
\text { w/1M sulfuric }\end{array}$ & $\begin{array}{c}\text { Baseline } \\
\text { w/0.25M nitric }\end{array}$ \\
\hline Time to fracture (s) & 67370 & 67938 & 68026 & 70270 & 64222 \\
Max load (lb) & $1835^{a}$ & 1827 & 1833 & 1841 & 1822 \\
Fracture strain (\%) & 47.5 & 47.9 & 48.0 & 49.5 & 45.3 \\
\hline
\end{tabular}

${ }^{a}$ An error in load cell recording of data required a modest "extrapolation” to record the specific value given. 
Table 7. Key parameters from the stress-strain curves for 2304 duplex stainless steel as a function of test environment

\begin{tabular}{lccccc}
\hline \multicolumn{1}{c}{2304} & Water & $\begin{array}{c}\text { Baseline } \\
\text { solution }\end{array}$ & $\begin{array}{c}\text { Baseline } \\
\text { w/iodine }\end{array}$ & $\begin{array}{c}\text { Baseline } \\
\text { w/1M sulfuric }\end{array}$ & $\begin{array}{c}\text { Baseline } \\
\text { w/0.25M nitric }\end{array}$ \\
\hline Time to fracture (s) & 52527 & 50227 & 58399 & 54419 & 59006 \\
Max load (lb) & $1681^{a}$ & 1735 & 1724 & 1730 & $\begin{array}{c}\text { Load cell } \\
\text { read-out lost }\end{array}$ \\
Fracture strain (\%) & 37.1 & 35.5 & 41.1 & 38.4 & 41.7 \\
\hline
\end{tabular}

${ }^{a}$ An error in load cell recording of data required a modest "extrapolation" to record the specific value given

Table 8. Key parameters from the stress-strain curves for 17-4 PH stainless steel as a function of test environment

\begin{tabular}{lccccc}
\hline \multicolumn{1}{c}{ 17-4 PH } & Water & $\begin{array}{c}\text { Baseline } \\
\text { solution }\end{array}$ & $\begin{array}{c}\text { Baseline } \\
\text { w/iodine }\end{array}$ & $\begin{array}{c}\text { Baseline } \\
\text { w/1M sulfuric }\end{array}$ & $\begin{array}{c}\text { Baseline } \\
\text { w/0.25M nitric }\end{array}$ \\
\hline Time to fracture (s) & $\begin{array}{c}\text { grips } \\
\text { slipped }\end{array}$ & 18622 & 22466 & 28707 & 31531 \\
Max load (lb) & 2447 & 2881 & 2888 & 2950 & 2914 \\
Fracture strain (\%) & 15.2 & 13.1 & 15.9 & 20.3 & 22.2 \\
\hline
\end{tabular}

Table 9. Key parameters from the stress-strain curves for $\mathrm{Zr}-4$ as a function of test environment

\begin{tabular}{lccccc}
\hline \multicolumn{1}{c}{ Zr-4 } & Water & $\begin{array}{c}\text { Baseline } \\
\text { solution }\end{array}$ & $\begin{array}{c}\text { Baseline } \\
\text { w/iodine }\end{array}$ & $\begin{array}{c}\text { Baseline } \\
\text { w/1M sulfuric }\end{array}$ & $\begin{array}{c}\text { Baseline } \\
\text { w/0.25M nitric }\end{array}$ \\
\hline Time to fracture (s) & 38193 & 39686 & 40096 & 35674 & 36025 \\
Max load (lb) & 1274 & 1268 & 1254 & 1265 & 1273 \\
Fracture strain (\%) & 26.9 & 28.0 & 28.3 & 25.2 & 25.4 \\
\hline
\end{tabular}

Table 10. Key parameters from the stress-strain curves for $\mathrm{Zr}-2.5 \mathrm{Nb}$ as a function of test environment

\begin{tabular}{lccccc}
\hline \multicolumn{1}{c}{ Zr-2.5Nb } & Water & $\begin{array}{c}\text { Baseline } \\
\text { solution }\end{array}$ & $\begin{array}{c}\text { Baseline } \\
\text { w/iodine }\end{array}$ & $\begin{array}{c}\text { Baseline } \\
\text { w/1M sulfuric }\end{array}$ & $\begin{array}{c}\text { Baseline } \\
\text { w/0.25M nitric }\end{array}$ \\
\hline Time to fracture (s) & 36714 & 33481 & 29055 & 31103 & 33795 \\
Max load (lb) & 1326 & 1438 & 1360 & 1405 & 1428 \\
Fracture strain (\%) & 25.9 & 23.6 & 20.5 & 21.9 & 23.8 \\
\hline
\end{tabular}

Further evidence that the mechanical properties of the materials are insensitive to the test environment can be seen in comparison of the complete stress-strain curves. Figure 15 shows three such curves plotted together for 316L stainless steel. The elastic behavior for each environment is identical, and 316L was observed to plastically deform remarkably consistently in each environment leading to essentially identical ultimate tensile strength values. Further, the large reduction in area prior to failure in each environment is consistent, with only a slight variation in the final load at failure (lowest for the specimen exposed in water). The inclusion of two additional curves-for the $1 \mathrm{M}$ sulfuric acid and the $0.25 \mathrm{M}$ nitric 
acid addition environments-does not enhance the plot as these curves fall identically on top of the others plotted at this scale. Similarly, Figure 16 compares the stress-strain curves for three environments for the $\mathrm{Zr}-4$ alloy. Consistent with the behavior of all the alloys examined, the similarity in these curves suggests no sensitivity to SCC.

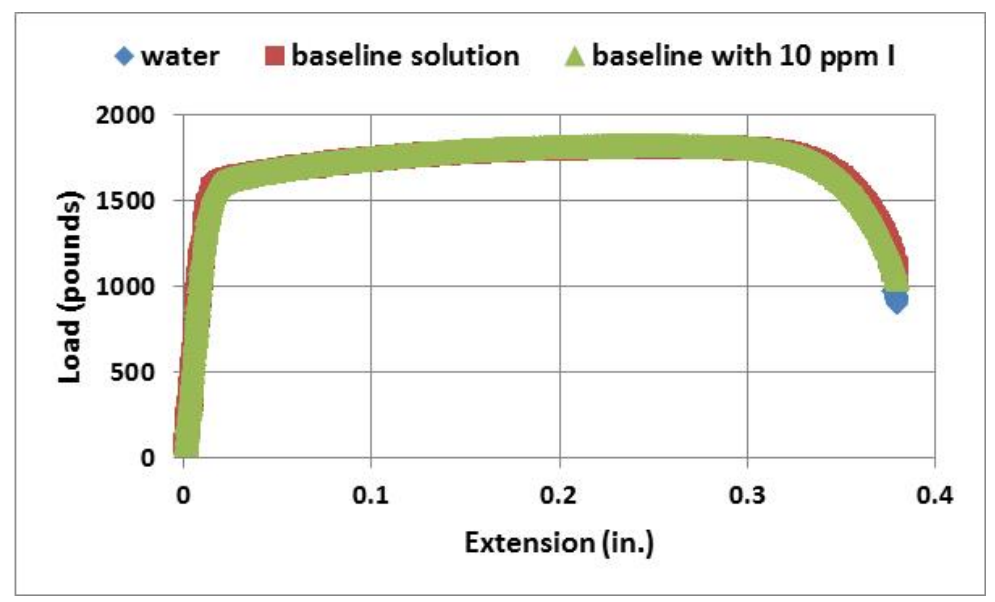

Figure 15. Stress-strain curves for 316L stainless steel as a function of test environment.

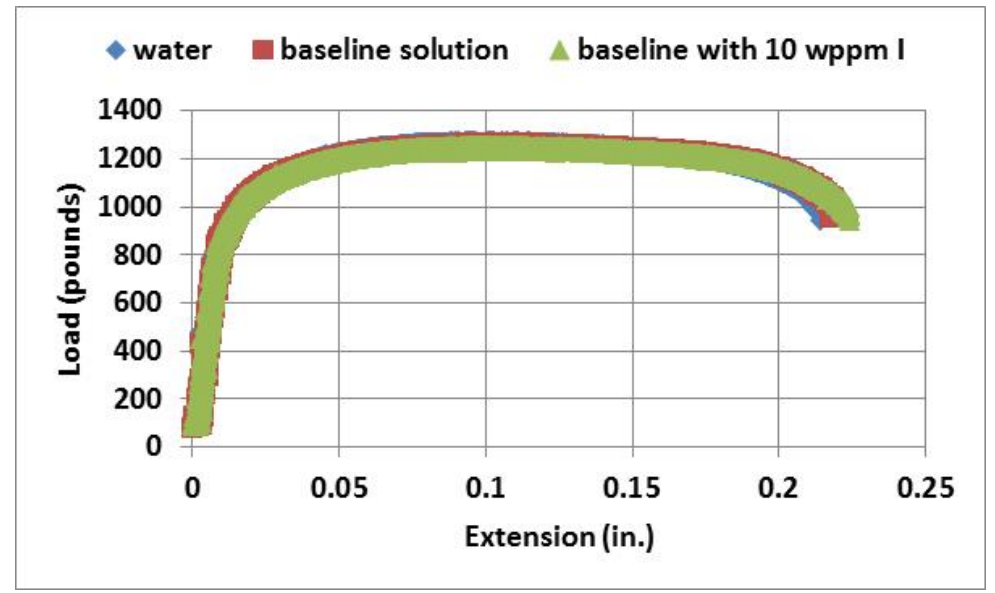

Figure 16. Stress-strain curves for $\mathrm{Zr}-4$ as a function of test environment.

Comparison of the fracture surface characteristics as a function of exposure environment also suggested no sensitivity to SCC among the alloys. A representative comparison for 316L stainless steel, correlating to the same three stress-strain curves shown in Figure 15, is presented in Figure 17. The macrographs indicate very uniform and nearly identical reduction in area — approximated by the dashed black line-for each specimen/environment combination. The edges of each specimen as well as the fracture faces are free of secondary cracks, further indicating no susceptibility to SCC. In addition, the characteristics of each fracture face-in this case, interspersed regions of micro-void coalescence and quasi-cleavage fracture advance-are nearly identical on each specimen, again suggesting the environment has little influence of fracture mechanisms. 

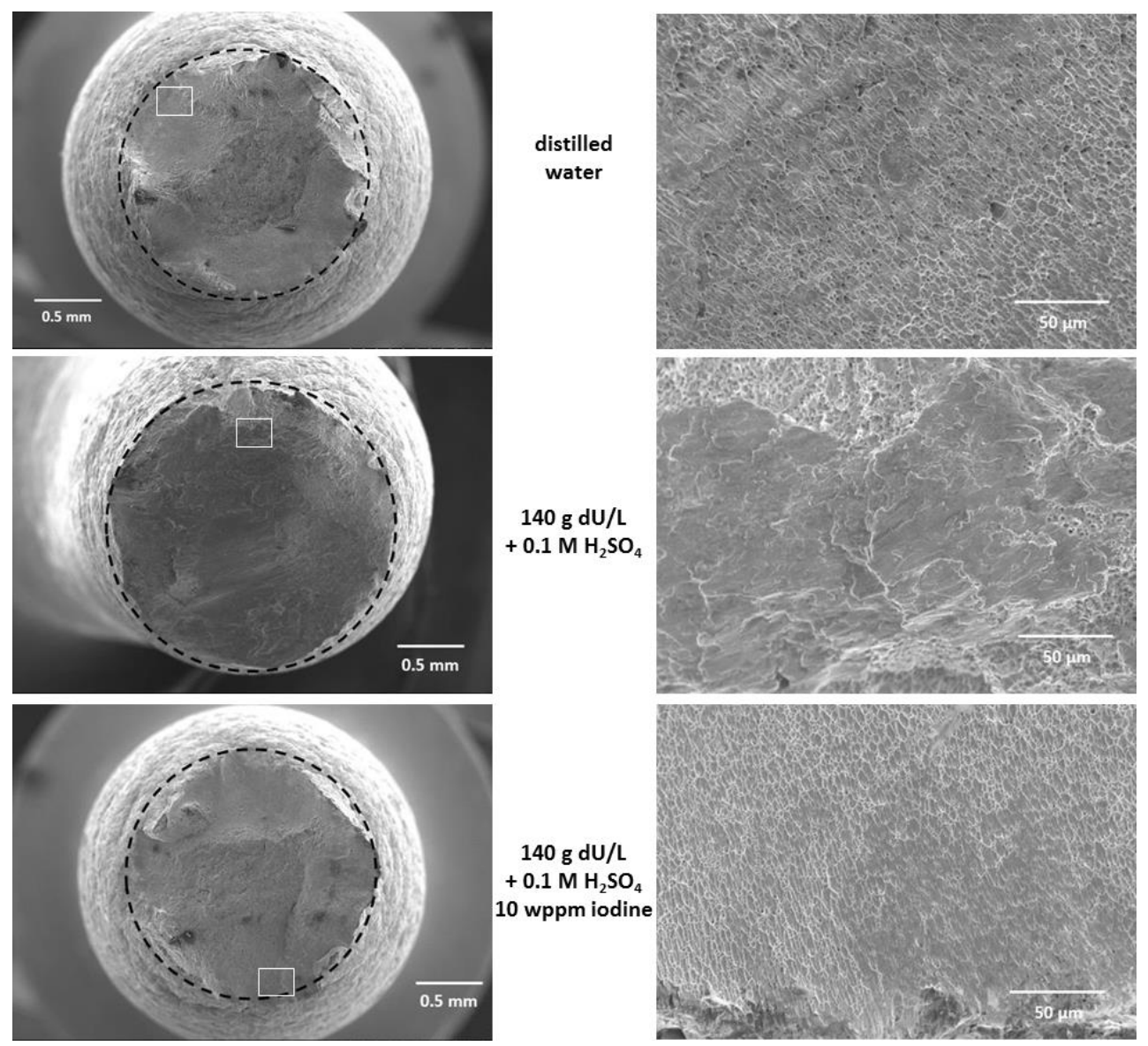

Figure 17. Fracture surface macrographs (left column) and representative fracture surface detail (right column) for 316 tensile specimens pulled to failure in three different environments. The approximate location of each high-magnification region is shown by the white box on the corresponding macrograph.

A similar representative collage of fracture information for $\mathrm{Zr}-4$ is presented in Figure 18. As was the case for 316L, the $\mathrm{Zr}-4$ specimens exhibited nearly identical reduction in area, no secondary cracking, and fracture surface details independent of test environment. Compared to the 316L specimens, the $\mathrm{Zr}-4$ specimens exhibited a somewhat oval final fracture area. While not examined in detail, it is suspected that the hexagonal crystal structure of the zirconium alloys and the slight texture in the specimens resulting from the original plate rolling contributed to the lack of uniformity in the reduction in area of the tensile specimens. The difference in the final cross section of the 316L and the $\mathrm{Zr}-4$ specimens is highlighted in Figure 19, which shows (to scale) the relative difference between the original dimensions/shape of the gage section area and the final cross-sectional area. For the three $\mathrm{Zr}-4$ alloys, the final reduction in area was essentially identical; for the 316L, the area reduction was slightly less for the specimen in the baseline solution but not sufficiently to suggest sensitivity to SCC. In all cases of 316L and Zr-4 specimens, the final reduction in area was at least $50 \%$ in every environment. 

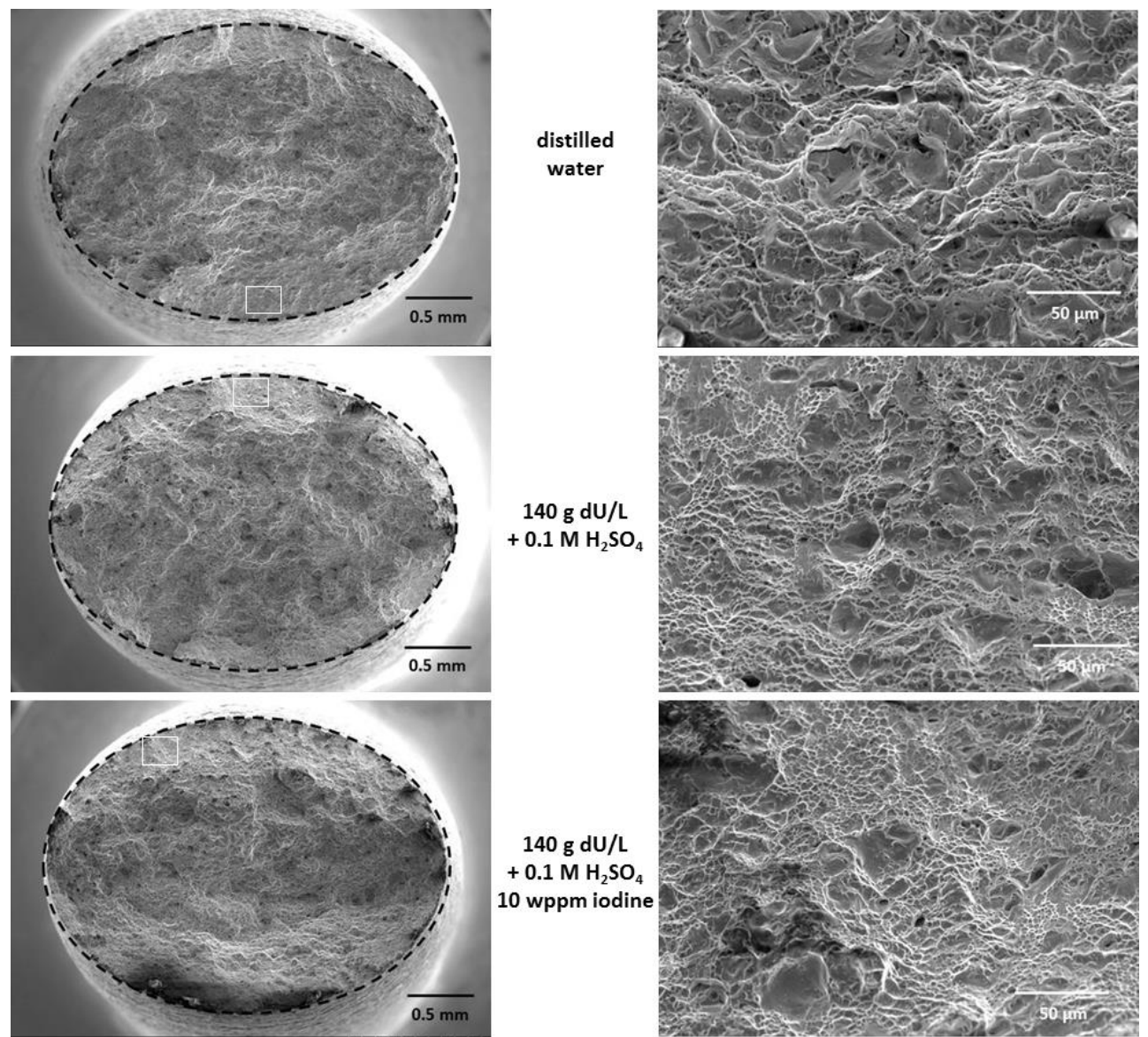

Figure 18. Fracture surface macrographs (left column) and representative fracture surface detail (right column) for $\mathrm{Zr}-\mathbf{4}$ tensile specimens pulled to failure in three different environments. The approximate location of each high-magnification region is shown by the white box on the corresponding macrograph.

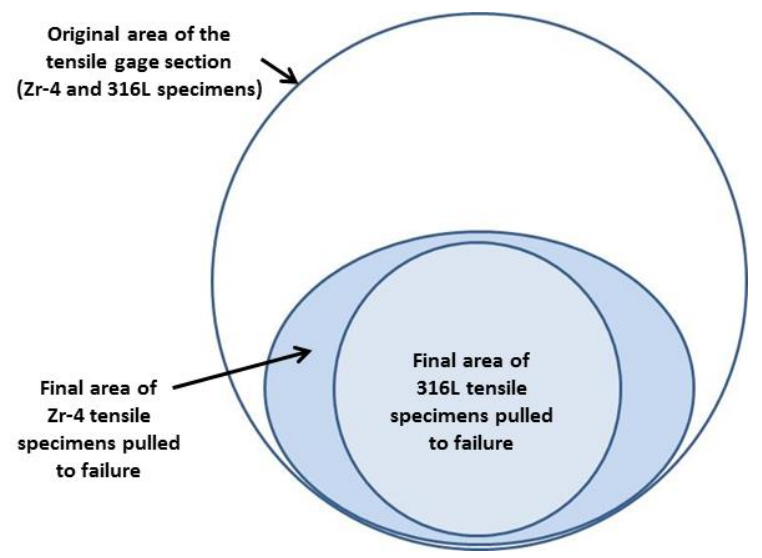

Figure 19. Schematic representation of the reduction in area for $316 \mathrm{~L}$ and $\mathrm{Zr}-4$ specimens resulting from the SSR tests. 


\subsection{ELECTROCHEMICAL POLARIZATION AND FLUID VELOCITY}

In a polarization test, the specimen is exposed to a large range of electrochemical potentials representing the full gamut of oxidizing and reducing conditions that might be encountered upon exposure to the generalized solution chemistry of interest. In the present case, such testing was pursued to assess and compare the general passivity characteristics of each candidate alloy as well as the relative susceptibility to localized corrosion such as pitting or crevice attack.

Since water is decomposed by high-energy ionizing radiation, yielding mainly hydrogen, oxygen, and hydrogen peroxide as well as perhaps several variably stable radicals comprised of oxygen and hydrogen, this process (termed radiolysis) could substantially alter the electrochemical potential of the environment and thus the corrosion characteristics of a metal so exposed. Depending on what specie(s) is formed in the process and its relative stability/concentration - which is determined by the spectrum/intensity of radiation and the chemical characteristics of the original aqueous solution-changes to the corrosion potential could be somewhat oxidizing or reducing or both at different times during the process. While some attempt to examine these situations has been incorporated into the testing to date-chiefly by modifications to the baseline solution to include 10 times the usual sulfuric acid concentration or the addition of $0.25 \mathrm{M}$ nitric acid-it is not practical to examine all the individual and specific possibilities of chemistry change that could alter the corrosion potential as a result of radiolysis. However, examination of the various candidate alloys in a polarization test—which examines the essentially instantaneous corrosion response of a material to a very wide range of electrochemical potentials in a relatively brief test-permits exposure to simulated radiolysis-driven changes within the test solution without making an undue number of "recipe" changes to the chemistry of the test environment.

Figure 20 shows a schematic polarization curve result for a metal displaying very simplified cathodic and anodic (corrosion) reactions. This figure enables identification of the key characteristics of interest in the present investigation of polarization behavior. Typically, the magnitude of the passive current density at any given potential (roughly correlates to corrosion rate in simplified interpretation) and the extent of the passive current region (generally measured in $\mathrm{mV}$ ) are the most significant features for the purpose at hand, along with the open circuit potential. Figure 21 shows schematic representations of likely changes in the polarization behavior that might result from changes in the environment. For example, loss of passivity or at least increased passive corrosion current as a result of increased fluid velocity is depicted on the left side of Figure 21. While the change indicated is purely schematic, conceptually it suggests that increased velocity perhaps refreshes the concentration of corrodants at the metal surface or adds a modest erosion component to the situation in a way that increases anodic current (corrosion) at nominally passive potentials. Similarly, as potential is increased, passivity can be lost in localized areas, resulting in a curve similar to that shown on the right in Figure 21. This type of behavior often results from pitting or crevice attack of the surface that can be caused by aggressive species in solution disrupting the passive film (halides are a common example) or increasing its solubility in the environment. 


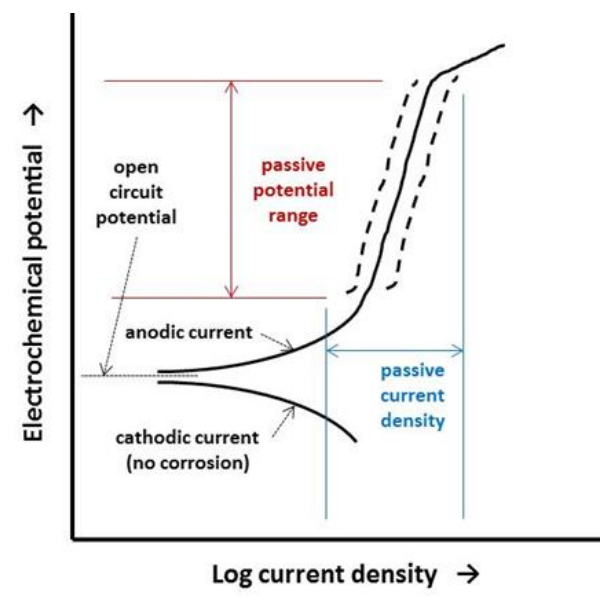

Figure 20. Schematic polarization curve for a material indicating simple passivity.
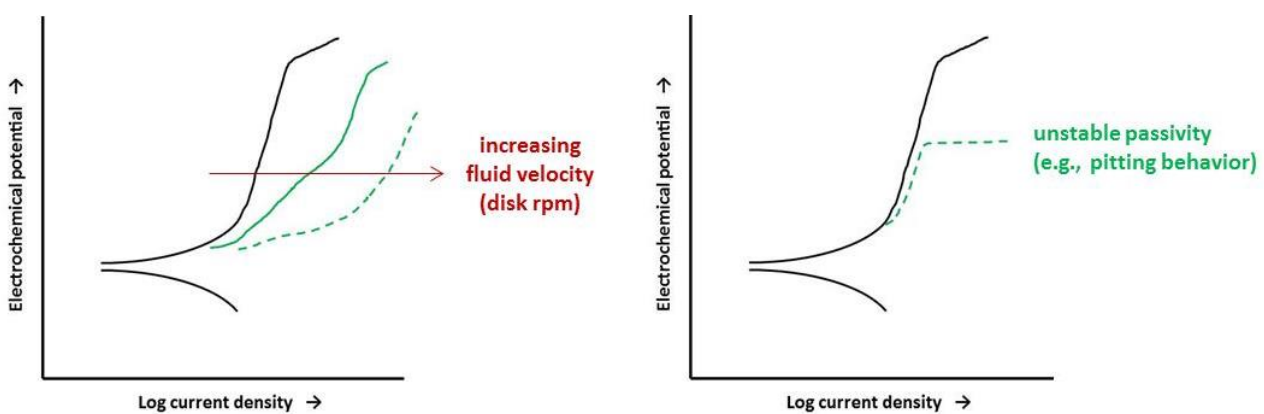

Figure 21. Schematic changes in polarization behavior that might result from increasing fluid velocity (left) or localized corrosion (right).

The most significant result in the polarization testing is that all the alloys examined, that is, both zirconium-based materials and 316L and 2304 stainless steels, were remarkably passive over a very wide range of potentials from the open circuit value to potentials at which water becomes electrochemically unstable. Further, there was no indication of sensitivity to localized corrosion (pitting) on any alloy, nor were these observations influenced at all by fluid velocity.

Figure 22 compares all four alloys in a standard polarization scan (no rotational velocity of the working electrode) in the baseline solution (140 g dU/L + $0.1 \mathrm{M}$ sulfuric acid) at room temperature. Slight variation in the open circuit potentials is a routine result of the nuances of precise surface condition (presence of an air-formed film and the extent to which it is removed by the brief cathodic cleaning treatment) and the variation in alloy composition. In particular, waiting only $\sim 1 \mathrm{~h}$ on open circuit potential equilibrium to be established invites some scatter in this measurement. However, based on the remarkably passive behavior that follows in the scan, the minor differences in open circuit potential are rendered inconsequential. Note that for all four alloys, the passive current density is very stable, as denoted by a nearly "vertical” line on the graph indicating current density (corrosion) is not changing much over a very wide range of potentials. This behavior is consistent with and expected from the previous immersion testing and SCC (U-bends) from which corrosion rates could be estimated. In the strictest sense, only corrosion rates at the open circuit potential can be derived from polarization curves [not actually calculated for these tests, but the data confirm all four alloys exhibit corrosion rates well below $25 \mu \mathrm{m} / \mathrm{y}$ ( $1 \mathrm{mil} / \mathrm{y})$ for all conditions examined]. While corrosion rates for other potentials cannot be 
precisely determined from the polarization curves (equilibrium no longer applies when the potential has been artificially altered), the approximate corrosion rates nevertheless are consistent with values well below $25 \mu \mathrm{m} / \mathrm{y}$, and that is true for potentials all the way to about $1 \mathrm{~V}$ positive to the saturated $\mathrm{Ag} / \mathrm{AgCl}$ electrode (at which water begins to break down electrochemically), indicating remarkable stability of the passive film on each alloy. Intentional addition of $10 \mathrm{wppm}$ iodine (half as $\mathrm{I}^{-}$from $\mathrm{KI}$ and half as $\mathrm{IO}_{3}{ }^{-}$ from $\mathrm{KIO}_{3}$ ), and perhaps smaller unintentional additions of chloride from the reference electrode (all of which leak a little bit), generated no change in the results indicated by Figure 22.

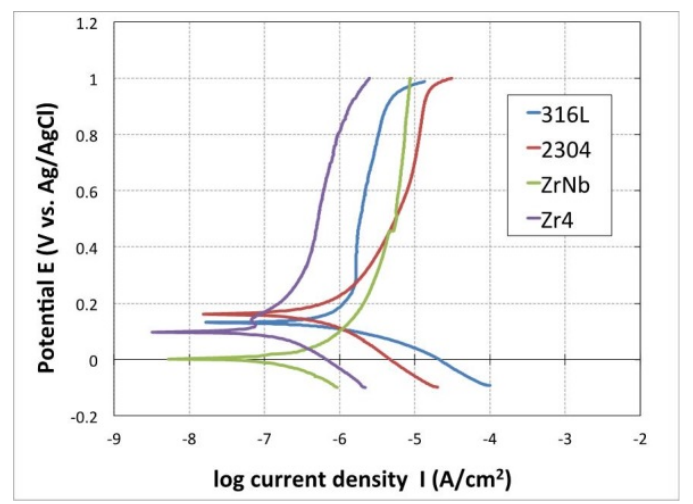

Figure 22. Comparison of polarization results at room temperature and zero rotational velocity for alloys in $140 \mathrm{~g} / \mathrm{L} \mathrm{dU}$ with $0.1 \mathrm{M}$ sulfuric acid added.

Figure 23 contains representative results of all the polarization tests as a function of the rotational speed of the electrode. These specific data, for $\mathrm{Zr}-2.5 \mathrm{Nb}$ in the baseline solution of $140 \mathrm{~g} \mathrm{dU} / \mathrm{L}$ with $0.1 \mathrm{M}$ excess sulfuric acid at room temperature, reveal only decreasing passive current densities as fluid velocity is increased, including the most rapid rate at which turbulent flow was apparent from the unstable formation of cavities/bubbles within the liquid. In contrast to the schematic possibility suggested by Figure 21, no adverse influence of solution velocity was observed for any alloy/environment combination. Further, no pitting (as indicated by the polarization curve or by observation of the post-exposure specimen surface) was detected for any alloy/environment/fluid velocity examined in this effort, including the limited exposures at $50^{\circ} \mathrm{C}$.

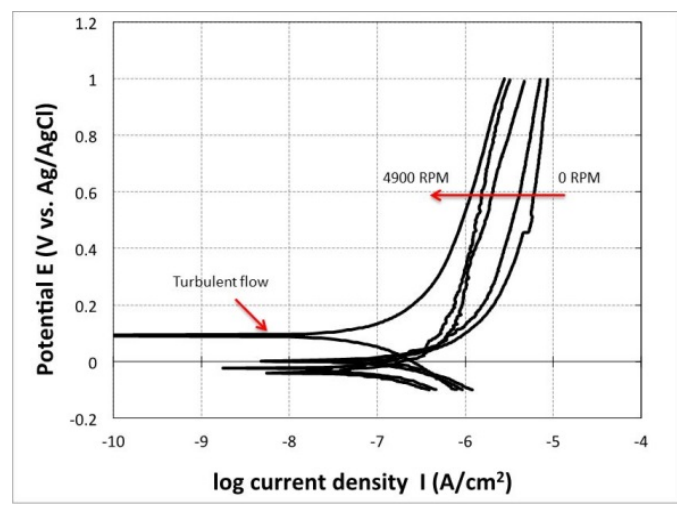

Figure 23. Polarization curves for $\mathrm{Zr}-2.5 \mathrm{Nb}$ at room temperature as a function of rotational speed of the working electrode. Individual rpm values incorporated in the plot were 0, 1600, 2500, 3600, and 4900.

In summary, the polarization data collected for these candidate alloys suggests extraordinary passivity over a wide range consistent with immeasurably low corrosion rates and with little or no influence of fluid velocity over the range of stagnant-to-turbulent conditions. Thus, while extreme fluid velocity is not 
expected within the SHINE process conditions, it appears unlikely that fluid velocity is a sensitive factor for consideration in the design and corrosion allowances that are developed.

\subsubsection{Vibratory horn}

Although cavitation conditions within the fluids are not expected in the SHINE process, limited vibratory horn testing was initiated in the previous year [1] that continued briefly into the FY 2015 effort reported herein. As before, the goal of the testing was simply to compare erosion-corrosion conditions for solutions with and without uranyl sulfate to consider any potential changes in compatibility that might result from fluid handling of these solutions. In the present cavitation testing, $140 \mathrm{~g} \mathrm{dU} / \mathrm{L}+1 \mathrm{M}$ excess sulfuric acid was compared with a similar density and $\mathrm{pH}$ solution prepared with $\mathrm{Na}_{2} \mathrm{SO}_{4}$ (same concentration of sulfate anion as for the uranyl sulfate) and modified with sulfuric acid to approximately the same $\mathrm{pH}$. The resulting density of the uranium-free solution $(1.18 \mathrm{~g} / \mathrm{ml})$ was slightly higher than that for the uranium-bearing solution $(1.16 \mathrm{~g} / \mathrm{ml})$.

The results can be summarized by the graphs in Figure 24, which show the response of Zr-4 and 316L to the cavitation exposure conditions. Of greatest significance is that in both these cases, the "steady state" weight change as a function of sonication time (slope of the virtual curve; following irregular incubation periods, a consistent weight loss rate seems to begin near $2 \mathrm{~h}$ of sonication for each alloy) is essentially identical for each material in the uranium-free solution and in the uranium-bearing solution. This indicates that the uranium component of the solution does not add a significant (potentially unanticipated) component to potential cavitation or related velocity effects in solution. As is evident in Figure 24, the total mass loss was actually slightly higher in the uranium-free solution; in fact, this was true for all five alloys examined, although the magnitude of the difference was substantially greater for 2304 and 17-4 PH alloys (as was the steady state weight change as a function of time). It is likely that the slightly higher density of the uranium-free solution is responsible for the generally slightly higher weight loss under cavitation conditions.
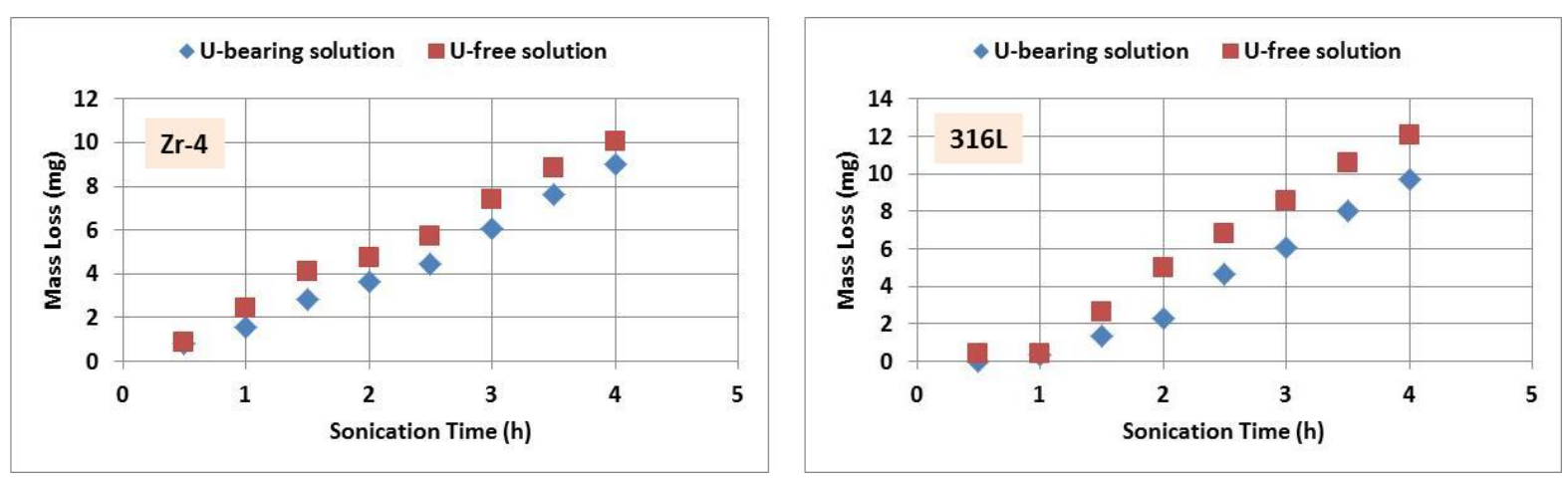

Figure 24. Weight loss as a function of sonication time for the $\mathrm{Zr}-4$ and $316 \mathrm{~L}$ specimens. Note that the total exposure time is actually twice the sonication time, because each exposure results from $10 \mathrm{~s}$ of sonication and $10 \mathrm{~s}$ of idle time in repeating cycles adding to a total of $1 \mathrm{~h}$. In the previous report [1], the cavitation weight loss plots did not distinguish between sonication time and total exposure time.

Post-test examination of the roughened specimen surfaces revealed generally poor correlation between the total mass loss (or steady state mass loss rate) and the average surface roughness on each specimen. To assess average surface roughness, the stage movement (focus) dial on a standard light microscope-which measures $\mu \mathrm{m}$ movement - was used to focus on the relatively highest and relatively lowest position on the surface within five randomly selected fields of view at 100×, and the results were averaged. Table 11 summarizes the available data. 
Table 11. Relationship between mass loss (steady state and total) and surface roughness in the erosioncorrosion exposure tests. Relative hardness of each alloy is also included for comparison

\begin{tabular}{|c|c|c|c|c|c|c|c|}
\hline \multirow{3}{*}{ Alloy } & \multirow{3}{*}{$\begin{array}{l}\text { Hardness } \\
\text { (DPH) }\end{array}$} & \multicolumn{6}{|c|}{ Summary cavitation test results } \\
\hline & & \multicolumn{2}{|c|}{$\begin{array}{c}\text { Average roughness } \\
(\mu \mathrm{m})\end{array}$} & \multicolumn{2}{|c|}{$\begin{array}{c}\Delta W \text { average in final } \\
\text { three tests }(\mathrm{mg} / \mathrm{h})\end{array}$} & \multicolumn{2}{|c|}{$\begin{array}{l}\text { Total } \Delta W \text { over } \\
\text { exposure (mg) }\end{array}$} \\
\hline & & U-free & U-bearing & U-free & U-bearing & U-free & U-bearing \\
\hline Zr-4 & 195 & 7 & 10 & 2.88 & 3.04 & 10.04 & 9.02 \\
\hline $\mathrm{Zr}-2.5 \mathrm{Nb}$ & 185 & 12 & 5 & 1.88 & 1.84 & 4.97 & 5.39 \\
\hline 316L & 205 & 8 & 8 & 3.52 & 3.40 & 12.09 & 9.67 \\
\hline 2304 & 215 & 17 & 12 & 9.52 & 2.64 & 45.25 & 7.61 \\
\hline 17-4 PH & 335 & 9 & 8 & 7.26 & 2.21 & 33.59 & 7.20 \\
\hline
\end{tabular}

Note that the surface roughness for four of five alloys is equal or lower in the uranium-bearing solution than for the uranium-free solution, and for $\mathrm{Zr}-4$ the plot of Figure 24 (and the similarity in steady state weight loss as well as total weight loss) confirms that the presence of uranium in the solution is not a threat to Zr-4 performance in an erosion-corrosion capacity. Curiously, the steady state weight loss rate and the total weight loss values do not correlate very well with alloy hardness. As a generality, higher hardness correlates to greater cavitation resistance, but the hardest alloy (17-4 PH) exhibited a relatively large weight loss_-but only modest surface roughening —indicating perhaps that corrosion during the "off" moments in the sonication cycles contributed a significant wastage component to the erosioncorrosion assessment or, alternatively, an oxide layer is intermittently lost during sonication periods. While the reasons are not clear, the performance of the 2304 in the uranium-free cavitation solution was quite unusual in that the weight change in each $1 \mathrm{~h}$ exposure (30 minutes sonication, 30 minutes free corrosion) varied wildly, from a low of just over $1 \mathrm{mg}$ to a high of over $16 \mathrm{mg}$, with no uniformity in trend. While this behavior is unexplained, the overall result remains that a uranium-bearing solution does not necessarily negatively influence cavitation wastage for this alloy (or any alloy in the examined conditions).

\subsubsection{Irradiation test conditions}

In FY 2015, only one irradiation test was completed after development of the test procedure and identification of an appropriate spent fuel bundle. The results are summarized in Table 12, which records the corrosion rates calculated from weight changes for specimens exposed in the baseline solution $\left(140 \mathrm{~g} \mathrm{dU} / \mathrm{L}+0.1 \mathrm{M}\right.$ sulfuric acid) or in the vapor above it for both radiolysis conditions $\left(67-69^{\circ} \mathrm{C}\right)$ and for laboratory testing in the absence of substantial gamma flux $\left(65^{\circ} \mathrm{C}\right)$. The data clearly suggest that an increase in corrosion rate is associated with the radiolysis exposure conditions, but even the largest corrosion rate among specimens exposed to radiolysis conditions was $<10 \mu \mathrm{m} / \mathrm{y}(<0.4 \mathrm{mil} / \mathrm{y})$. No change in surface roughness or development of pitting was detected on any of specimen exposed to radiolysis conditions, and the original machining marks remained readily visible on all specimens. Consistent with non-radiolysis exposures, the zirconium-based alloys developed a very thin, light straw/brown film while the stainless steel specimens revealed little visible change in surface coloration or gloss. Figure 25 shows the post-exposure appearance of all the specimens from the radiolysis exposure. 
Table 12. Comparison of corrosion rates $(\mu \mathrm{m} / \mathrm{y})$ derived from weight change resulting from exposures with and without intense gamma radiation (and thus potential radiolysis)

\begin{tabular}{lcc|cc}
\hline \multirow{2}{*}{ Alloy } & \multicolumn{2}{c|}{ Immersion position } & \multicolumn{2}{c}{ Vapor phase position } \\
\cline { 2 - 5 } & $\begin{array}{c}\sim \text { no radiolysis } \\
\text { (laboratory testing) }\end{array}$ & $\begin{array}{c}\text { potential radiolysis } \\
\text { (spent fuel pool) }\end{array}$ & $\begin{array}{c}\sim \text { no radiolysis } \\
\text { (laboratory testing) }\end{array}$ & $\begin{array}{c}\text { potential radiolysis } \\
\text { (spent fuel pool) }\end{array}$ \\
\hline $316 \mathrm{~L}$ & $<1.3$ & $5.3-6.9$ & $<1.3$ & $2.8-5.1$ \\
2304 & $<1.3$ & 9.4 & & 4.3 \\
$17-4 \mathrm{PH}$ & & 1.8 & & 2.3 \\
Zr-4 & $<1.3$ & 3.6 & $<1.3$ & 4.3 \\
Zr-2.5Nb & $<1.3$ & 6.6 & $<1.3$ & 2.3 \\
\hline
\end{tabular}
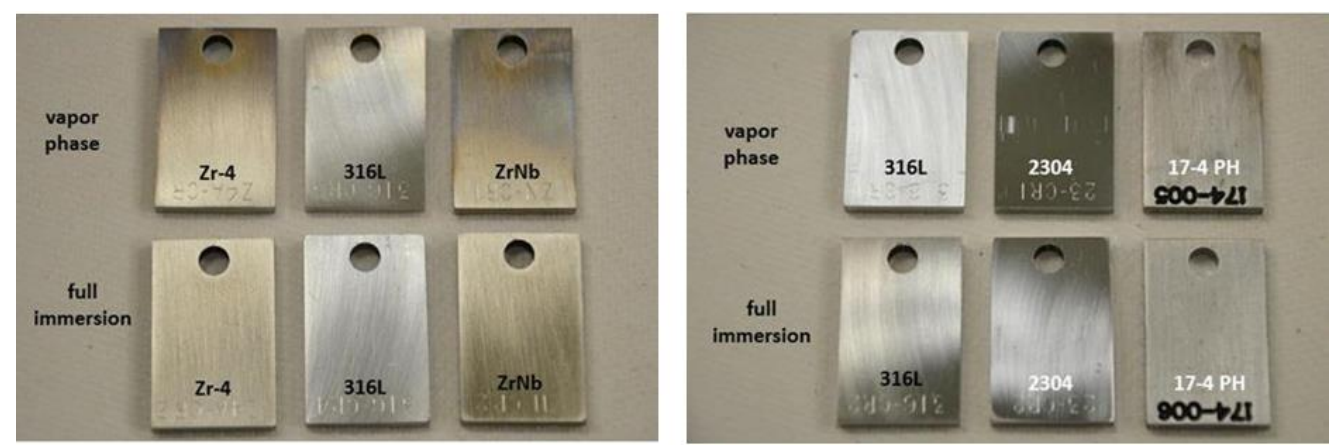

Figure 25. Post-exposure appearance of the specimens exposed to potential radiolysis conditions.

The projected dose experienced by the specimens in the week-long radiolysis experiment is large and comparable to that expected in the actual SHINE service exposure. As a result, the data presented here suggest that the candidate materials examined for SHINE service are quite resistant to solution changes resulting from radiolysis and thus such processes are not likely to generate corrosion and compatibility concerns for the materials of construction. Although the project work is in "close-out" mode at this writing, a few additional experiments are planned in FY 2016 in the spent fuel pool to further examine radiolysis possibilities.

\section{CONCLUSIONS}

A battery of U-bend SCC tests was performed in nine different solutions and at two different temperatures representing a range of potential SHINE process solution chemistries. For the stainless steel alloys, independent of exposure position — that is, fully immersed or in the vapor above the test solution-no cracking was detected for any specimens and no surface roughness changes were observed on any specimens. Further, weight changes and discoloration were uniformly consistent with observations made for similar exposures of unstressed specimens. Likewise, for the zirconium alloys, no cracking was observed on any specimens and no surface roughening was detected as a result of exposure. Weight change during the experiment was influenced by the initial surface condition of the alloy-whether or not the film formed during the machining process was allowed to remain-but the results were not appreciably different in either case compared to observations made on unstressed specimens.

Slow strain rate testing of candidate alloys was also performed at room temperature in a number of process solution chemistries. The mechanical properties of each alloy-such as ultimate tensile strength, elongation at failure, and reduction in area — and physical features such as fracture surface characteristics were found to be totally independent of test environment. In combination with the U-bend testing, this 
result suggests that the candidate alloys are not sensitive to SCC in the environments anticipated for the SHINE process.

Electrochemical polarization testing was performed on candidate alloys in prototypic solutions at ambient temperature and $50^{\circ} \mathrm{C}$ to examine passivation characteristics across a wider range of conditions that can be simulated within specific individual solution formulations. The results indicate that the alloys are robustly passive over a very wide range of potentials in relevant solutions up to near the electrochemical stability limit for water. Further, no susceptibility toward localized corrosion (e.g., pitting or crevice attack) was observed during the polarization scans or in post-test observations of the specimen surface.

The electrochemical polarization studies were also performed as a function of rotating disk speed (rpm of the test electrode) to examine solution velocity as a potential factor influencing corrosion and passivity. The results indicate that passivity is not degraded or altered significantly over a range of solution velocities from stagnant to $\sim 3 \mathrm{~m} / \mathrm{s}$ (the highest values of which appeared to be turbulent flow), and in fact, passivity is slightly enhanced (lower current density at a particular potential) as a result of relatively higher fluid velocity across the electrode surface.

Limited additional testing with the vibratory horn to examine the potential for damage in cavitation conditions was also incorporated. While cavitation conditions are not expected within the SHINE operating envelope, tests were performed to compare erosion-corrosion results for uranium-bearing solutions with similar solution chemistries ( $\mathrm{pH}$, sulfate concentration) without uranium to consider whether the presence of uranium in solution was particularly detrimental to wastage. Results indicate that the presence of uranium in solution does not accelerate cavitation damage compared to similar solutions without uranium.

Exposure of specimens under conditions potentially incorporating radiolysis was also initiated. Specialized containers were designed and placed within the flux trap of spent fuel cores in the storage pool at the HFIR. In the initial exposure ( 1 week at $\sim 67-69^{\circ} \mathrm{C}$; immersion and vapor phase exposures), the corrosion rates based on mass loss of all candidate alloys were very slightly higher under intense gamma irradiation than in equivalent exposures in the laboratory without this flux, but in all cases, the annualized corrosion rates were below $10 \mu \mathrm{m} / \mathrm{y}$, with no change in surface roughness and no discoloration that was not also observed in the laboratory testing.

\section{REFERENCES}

1. S. J. Pawel, "Corrosion Assessment of Candidate Materials for the SHINE Subcritical Assembly Vessel and Components - 2014 Report,” Oak Ridge National Laboratory Technical Memorandum ORNL/TM-2014/556, October 2014.

2. Standard Practice for Making and Using U-Bend Stress-Corrosion Cracking Specimens, ASTM Standard G30, American Society for Testing and Materials, West Conshohocken, PA, 1990.

3. Standard Practice for Descaling and Cleaning Zirconium and Zirconium Alloy Surfaces, ASTM Standard B614, American Society for Testing and Materials, West Conshohocken, PA, 2010.

4. P. R. N. Childs, Rotating Flow, Elsevier Publishing, Boston, MA (2011).

5. Standard Method of Vibratory Cavitation Erosion Test, Standard ASTM G32, American Society for Testing and Materials, West Conshohocken, PA, 2009

6. Series of private communications via electronic mail, E. N. Van Abel to S. J. Pawel, culminating with final details provided 12/18/2015. 